\title{
Design and Acoustic Efficacy of a Broadband Liner for the Inlet of the DGEN Aero-propulsion Research Turbofan
}

\author{
Daniel L. Sutliff* \\ NASA Glenn Research Center \\ Cleveland, Ohio, 44135 \\ Douglas M Nark ${ }^{\dagger}$, Michael G. Jones ${ }^{\ddagger}$, and Noah H. Schiller ${ }^{\S}$ \\ NASA Langley Research Center \\ Hampton, VA 23681
}

\begin{abstract}
Advanced fan designs (including higher bypass ratios) and shorter engine nacelles have highlighted a need for increased fan noise reduction over a broader frequency range. With these observations in mind, an acoustic liner optimization process has been developed to achieve improved broadband liner designs. A series of advanced liner design studies at increasing technology readiness levels have been conducted as the overall optimization methodology has been enhanced. As part of the analysis, the overall design and evaluation capability was extended such that external observer locations may be included in the optimization process. This enhancement will provide a much wider design space in designing advanced broadband liners. In this work, further validation was pursued through the fabrication and testing of two liner designs for the NASA Glenn DGEN Aero-propulsion Research Turbofan (DART). The DART was used to document the efficacy of acoustic liners installed in the inlet of the DGEN380. An advanced Multi-Degree of Freedom Liner was designed, fabricated, and tested, along with a traditional Single-Degree-of-Freedom liner, and those results compared to a hardwall baseline inlet. Farfield acoustic data were acquired from an external array, evaluated and reported herein terms of overall, broadband, and tonal components of the insertion loss. The predicted attenuation results generally matched expected trends of the measured data for the conditions considered.
\end{abstract}

\begin{tabular}{llll} 
& \multicolumn{2}{c}{ NOMENCLATURE } \\
AAPL & - Aero-Acoustic Propulsion Laboratory & LTF & - Liner Test Facility \\
BPF & - Blade Passage Frequency & MDOF & - Multi-Degree-of-Freedom \\
$C D L$ & - CDUCT-LaRC & LaRC & - Langley Research Center \\
$C D U C T$ & - C & RHS & - Right Hand Side \\
$D A R T$ & - DGEN Aero-propulsion Research Turbofan & SDOF & - Single-Degree-of-Freedom \\
$E G T$ & - Exhaust Gas Temperature & SPL & - Sound Pressure Level \\
$F A D E C$ & - Full Authority Digital Electronic Control & OAPSL & - Overall Sound Pressure Level \\
$H W$ & - Hardwall & PWL & - Acoustic Power Level \\
$H P T$ & - High-Pressure Turbine & RPMc & - Revolutions per Minute corrected \\
LHS & - Left Hand Side & TRL & - Technology Readiness Level
\end{tabular}

\section{Introduction}

$T_{\mathrm{h}}^{\mathrm{h}}$ he utilization of advanced fan designs (including higher bypass ratios) and shorter engine nacelles has highlighted a need for increased fan noise reduction over a broad frequency range. Thus, improved broadband liner designs must account for these constraints and take advantage of novel liner configurations. With these observations in mind, the development and assessment of a broadband acoustic liner optimization process has been pursued through a series of recent design and experimental studies ${ }^{1,2,3,4,5,6,7}$.

\footnotetext{
*Aerospace Engineer, Acoustics Branch, AIAA Associate Fellow.

${ }^{\dagger}$ Senior Research Scientist, Structural Acoustics Branch, AIAA Associate Fellow

${ }^{\ddagger}$ Senior Research Scientist, Structural Acoustics Branch, AIAA Associate Fellow

${ }^{\S}$ Research Scientist, Structural Acoustics Branch, Research Directorate
} 
In this design process, an acoustic duct propagation code is used to predict optimum impedance spectra over a number of frequencies and flow conditions. Acoustic liner modeling tools are then used to identify geometric liner parameters (within manufacturing constraints) necessary to produce impedance spectra that most closely match the predicted optimum values. The resultant impedance values are then used with the propagation code to predict attenuation spectra. Iteration between the prediction and design stages is possible to allow refinement of the liner design (e.g., to account for manufacturing constraints).

To gain further confidence in the tools used within the broadband liner design process, a series of multidegree of freedom (MDOF) liner design studies at increasing technology readiness levels (TRL) have been conducted as the overall optimization methodology has been enhanced. Initial liner designs targeting the NASA Langley Liner Technology Facility ${ }^{8,9}$ (LTF) resulted in predicted optimum impedance spectra consistent with those obtained using higher-fidelity, more computationally intensive models ${ }^{10}$. Subsequent design and testing in the NASA Glenn Advanced Noise Control Fan (ANCF) Rig ${ }^{3,4}$ and 9-ft x 15-ft Low Speed Wind Tunnel ${ }^{5,6}$ provided further confidence in the design process. Based on these results, additional validation was pursued through the fabrication and testing of liner designs for the NASA Glenn DGEN Aero-propulsion Research Turbofan (DART) and is the focus of this work. Further discussion of the DART and Aero-Acoustic Propulsion Laboratory (AAPL) may be found in earlier papers ${ }^{11,12}$. Although presented in a previous paper as well, the computational approach, impedance modeling, and liner design process are briefly described in more detail in Sections II and III respectively. This latest test configuration and associated measurements are described in Section IV. Evaluation of liner performance and comparison with predictions are provided in Section V. Finally, concluding remarks regarding some of the more significant results and further areas of interest are presented in Section VI.

\section{Acoustic Predictions}

As mentioned above, the liner design process is described in a previous paper ${ }^{13}$. However, it is useful to provide a brief overview of the methodology for completeness. For the current investigation, the majority of the duct propagation and radiation predictions were conducted using the CDUCT-LaRC (CDL) code. This code calculates the propagation of a given acoustic source ahead of the fan face or aft of the exhaust guide vanes in the inlet or exhaust ducts, respectively. Subsequent to the propagation calculations, the code has the capability of computing the noise radiation field outside the duct. The three-dimensional duct may include acoustic treatment (possibly circumferentially and radially segmented) and incorporate struts/bifurcations.

While CDL can accept arbitrary source specification (i.e., it is not a modal code), it is convenient to specify the acoustic source distribution in terms of duct modes. For situations in which the source pressure is available, this greatly simplifies conversion to the required acoustic potential. However, an assumption on the source description must be made when source information is unavailable (as was the case when the liner design process began).

Therefore, as discussed in a previous CDL study ${ }^{14}$ a statistical source model was employed. As part of this approach, 11 simulations were performed for each configuration and condition to produce a sample population from which statistical information can be inferred.

As with previous liner optimization studies ${ }^{1,3,5}$, induct attenuation was chosen as the cost function for the impedance optimization. Thus, optimum impedance values were predicted using the propagation module of the CDL code (with the aforementioned source model) coupled with optimization routines. This was accomplished by using the Python programming language (http://www.python.org) to "wrapper" the CDL calculations. The use of the Python scripts allows access to the full set of tools available in the optimization package of the SciPy ${ }^{15}$, library.

The impedance prediction model used in this study combines two models presented in an earlier paper ${ }^{16}$. The first is a transmission line model ${ }^{17}$ that assumes acoustic wave propagation through each layer of the liner (see Figure 1) and the second is a lumped element model ${ }^{18,19,20}$ used to compute the impedance change across perforates. The normalized surface impedance spectra presented by each chamber of the liner are computed separately, and are then combined to determine an effective surface impedance spectrum that is assumed uniform across the liner surface. 


\section{Liner Designs}

As indicated above, the CDL propagation code was used to determine target optimum impedance values, $\zeta_{\text {opt }}\left(f_{i}\right)$, at selected frequencies, $f_{i}$, for a given flow speed over a design space encompassing $0<\Theta \leq 5$ and $-10<\chi \leq 10$. With this being the first operational test of DART, limited information was available on DART source content and flow conditions. Therefore, target values were obtained at one-third octave center frequencies ranging from 1000 to $8000 \mathrm{~Hz}$ at a flow condition expected to be nominally representative of $100 \%$ of design RPMc ( $M=0.5$ at the fan face). The efficiency of this process allows for parallelelement, variable-impedance, broadband liner concepts at various technology readiness levels (TRL) to be considered for implementation. Therefore, it is expected that updated liner designs with improved broadband noise reduction will be produced as additional DART information becomes available.

To achieve the desired broadband performance, candidate liner designs consisted of multi-layer configurations incorporating septa (or "mesh-caps") embedded into a honeycomb core ${ }^{21}$. This concept allows the acoustic liner to be customized such that the surface impedance of each individual cell is independently controlled. This is achieved by the combination of parameters used to set the impedance in each cell (Figure 1). Clearly, manufacturing constraints (e.g., liner geometric parameters such as porosity and core depth) are key ingredients in this modeling phase, and must be taken into account to design acoustic liners that can be realistically achieved. In this study, the honeycomb cells were allowed to contain up to two mesh-caps. The mesh cap depths, as well as DC flow resistances, were allowed to vary from cell to cell. The liner modeling tools were used to obtain design impedance values, $\zeta_{\text {pred }}\left(f_{i}\right)$.

A number of MDOF liner concepts were considered. However, manufacturing liners for the DART inlet represents a unique challenge. Because of the small diameter of the DGEN380 fan ( 14 inches), it becomes a significant challenge to bend the core to achieve a flush fit. This limited some of the choices for manufacturing of the liners. Therefore, consideration was made to select liners allowing acquisition of sufficient data to demonstrate the validity of the liner design process, and to gain insight that could be used to better optimize liners for future tests with this engine. Ultimately, two liner concepts were selected for this study. Figure 2 is a close-up photo of the liner cores. The first, shown in Figure 2a, is a 2DOF liner that contains a septum with a resistance sufficiently high to effectively eliminate sound transmission into the lower chamber. Thus, from an acoustics point of view, it should be considered as an SDOF liner. The second, shown in Figure 2b is a 3DOF liner that contains two septa in each honeycomb chamber. Each septum has a unique resistance and location within the chamber, and the same distribution is used in each chamber.

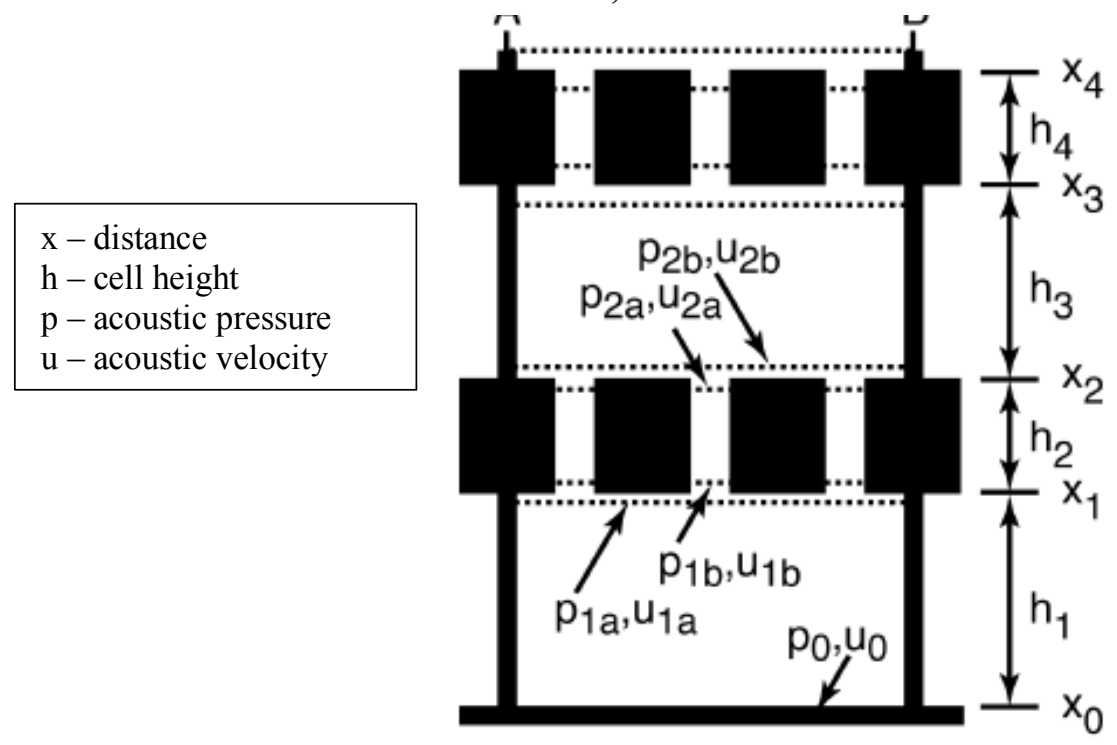

Figure 1: Sketch of Liner Single Chamber with Key Parameters for Transmission Line Impedance Prediction Model 


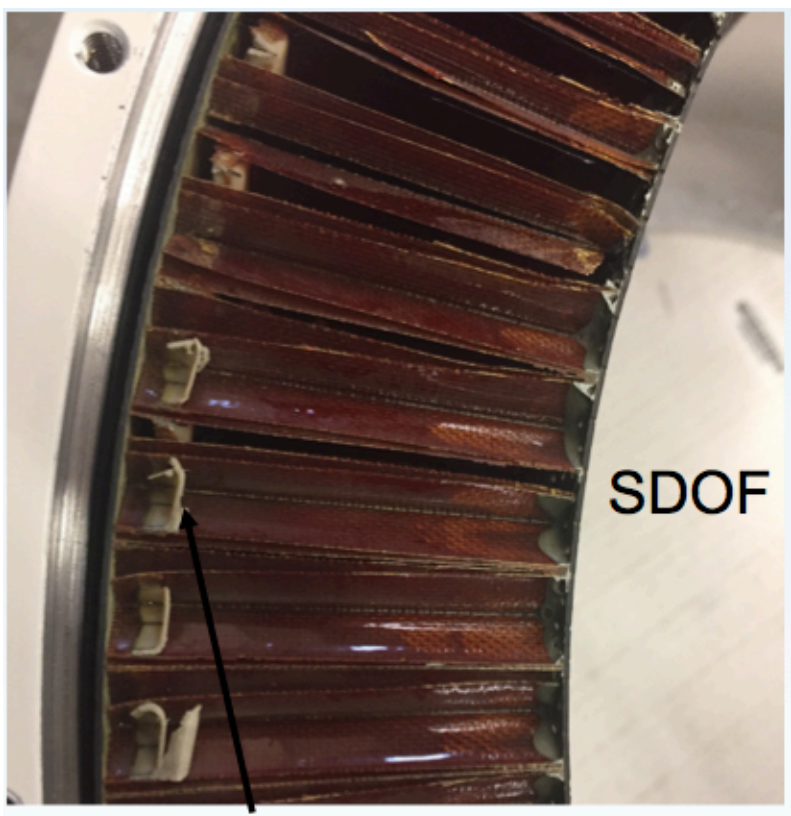

Septa: very high resistance Essentially HW to set cavity depth

(a) SDOF Liner Core

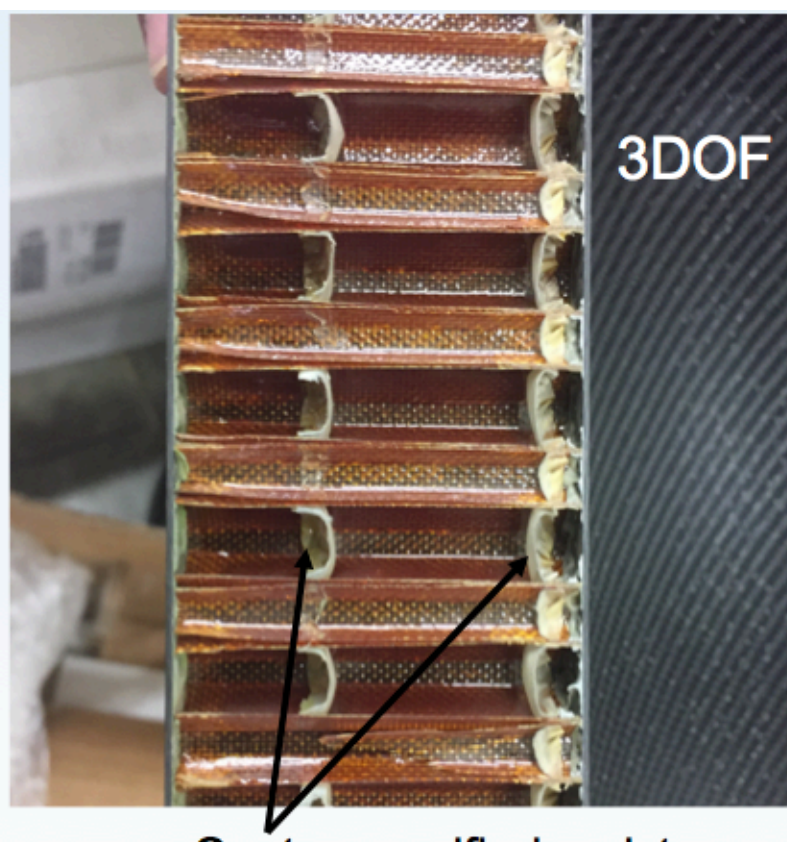

Septa: specified resistance To create 3 cavities

(b) MDOF Liner Core

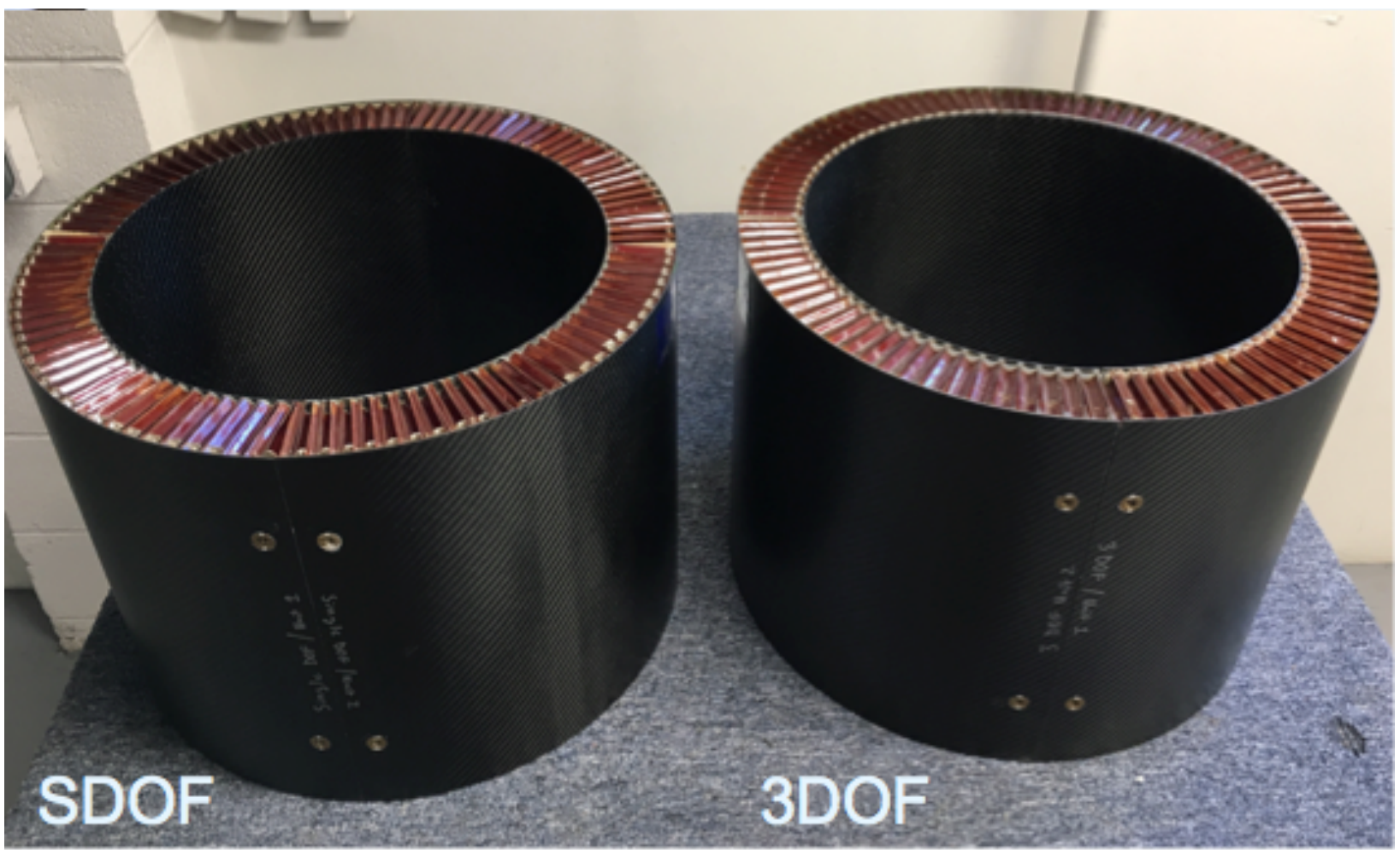

(c) Assembled Liner Core

Figure 2: Photos of Liner Cores 


\section{Experimental Setup}

\section{A. Aero-Acoustic Propulsion Laboratory Facility}

The AAPL dome ${ }^{22}$ is 65 -feet high and 130 -feet in diameter, providing an anechoic testing environment for engine component research and development. To provide an anechoic environment, custom-designed 2-foot thick fiberglass wedges are mounted on the dome's interior walls and floor areas adjacent to the test rigs. These wedges provide an anechoic environment down to $125 \mathrm{~Hz}$. Figure 3 shows the AAPL facility from the outside looking in.

\section{B. DGEN Aeropropulsion Research Turbofan}

The Price Induction DGEN380 (Figure 4) is the primary component integrated into the NASA Glenn Research Center's DGEN Aero-propulsion Research Turbofan (DART). It serves as a flexible, relevant, experimental aeroacoustic and aero-performance test bed and can provide valuable information throughout NASA's technology maturation process. The DGEN380 engine is a high bypass ratio (7.6) turbofan engine designed for powering small personal jets. The engine features a two-spool flow architecture with a 3.32 ratio gearbox that links the low-pressure turbine to the fan spool. The high-pressure turbine runs the compressor and reaches rotational speeds up to about 50,000 revolutions per minute (RPM).

The DGEN380 was integrated into the AAPL facility by mounting the engine and its associated pylon on a platform. Figure 5 is a schematic of the DART system showing the two locations where the DGEN380 component of DART can be located. For this test program, DART was located in the center location.

Measurement of the initial acoustic baselining of the DART is presented in references ${ }^{23,11,12}$.

The Full Authority Digital Electronic Control (FADEC) automatic sweep was programmed to achieve $50 \%$ through $90 \%$ (at $10 \%$ intervals), $92.5 \%$ then $95.6 \%$, return to $50 \%$, and then repeat the $95.6 \%$ corrected fan RPM, as shown in Table I. This $95.6 \%$ max speed (and repeat) was initially chosen based on this being the max continuous high-pressure turbine (HPT) speed permitted at standard day conditions (higher HPT speeds would be time-limited for brief durations such as take-off). However, operating on hotter days, and the addition of an internal containment shield for the turbine tri-hub failure (extremely unlikely - but an additional safety requirement when operating in a research paradigm) resulted in the inability to reach $95.6 \%$ consistently. The automatic sweep was programmed to stop at a designated maximum exhaust gas temperature (EGT), which often was lower than 95.6\% (See Table I).

\section{Farfield Array}

Acoustic data were acquired using 30 microphones, which were located on a 10-foot radius arc at the engine vertical centerline. This arc was in two segments; a forward arc centered about the inlet plane, and an aft arc centered about the bypass nozzle exit plane. The microphones in this arc were $1 / 4$ "-Electret-style PCB ${ }^{\circledR}$ model 130E20 microphones. These microphones were TEDS ${ }^{\circledR}$ capable current-supplied at 6 mA. Figure 6 shows this array relative to the DGEN380 location and Table II lists the geometric information.

The time-histories were acquired using the microphones at a sampling frequency of $250 \mathrm{kHz}$ using a 40 $\mathrm{Hz}$ to $50 \mathrm{kHz}$ band-pass filter on a HBM GEN2i ${ }^{\circledR}$ data acquisition recorder. The acquisition time was 15 seconds at each engine speed point in the pre-programmed automatic sweep. The data analysis method used in this paper is based on the technique recently developed by Sree and Stephens ${ }^{24}$. The technique was developed to separate tone and broadband noise components from raw acoustic data generated from a hobby mini open-rotor having 4-forward and 3-aft blades, and a counter-rotating open-rotor model (F31A31) having 12 forward and 10 aft blades ${ }^{25}$.

\section{Liner Installation}

An inlet spool was designed and manufactured by the DGEN380 vendor, Price Induction, to accommodate the liner cores. The liner cores were placed in a liner-holder spool. As shown in Figure 7 and Figure 8, this holder was a full cylinder with a removable end cap that allowed for insertion of the liner. This spool had a pocket extending from the outer flow path to accommodate the liner cores. A removable end cap was incorporated to allow for quick insertion/removal of the liner cores. and illustrate the liner spool holder. 
Figure $7 \mathrm{a}$ and $7 \mathrm{~b}$ are drawings of the holder-spool, with the end cap shown in red. The depth of the holder was chosen to allow for some future additional liner concepts to be tested. Figure 8a shows the thin walled, hard-wall, inlet extension spool - this spool is the same axial length as the liner holder spool to provide a new hardwall baseline. Figure $8 \mathrm{~b}$ is a photo of the liner-holder spool with a core installed and the end cap fastened. Figure 9 is a drawing illustrating the liner spool holder in the DGEN380 inlet. Figure 10 is a photo of the extension spool installed in the inlet of the DGEN380 engine.

The hardwall inlet insert was tested first to re-baseline the acoustic levels resulting from the additional inlet length. An insert was chosen because the project window time-line did not allow for a design to be integrated into the DGEN lip/forward fan casing or the more complicated exhaust environment (for which the MDOF liner design concept is actually more suited). Thus, the paradigm was to evaluate the insertion losses of the liners and compare to the predictions as a validation of the concept and design tools, not necessarily as a direct proof of greater efficacy of the MDOF to SDOF liners. It is the view of the authors that the MDOF liner design concept is more suited to the exhaust acoustic/flow environment, but the aforementioned restrictions resulted in the selection of the inlet for this initial study.

The two liners were then tested sequentially. The same automated FADEC programmed corrected fan speed points were acquired for all three configurations (Table III).

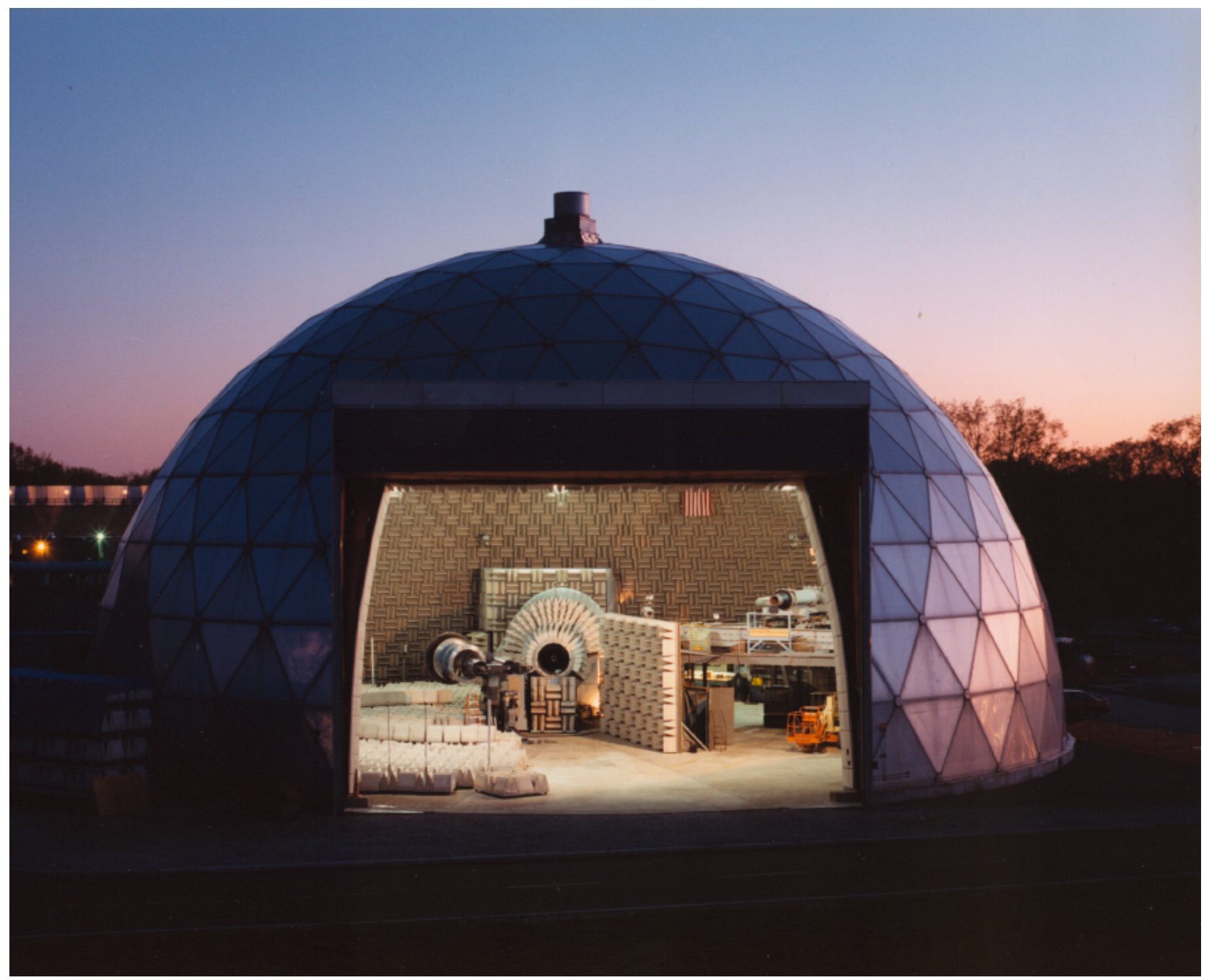

Figure 3: Aero-Acoustic Propulsion Laboratory 

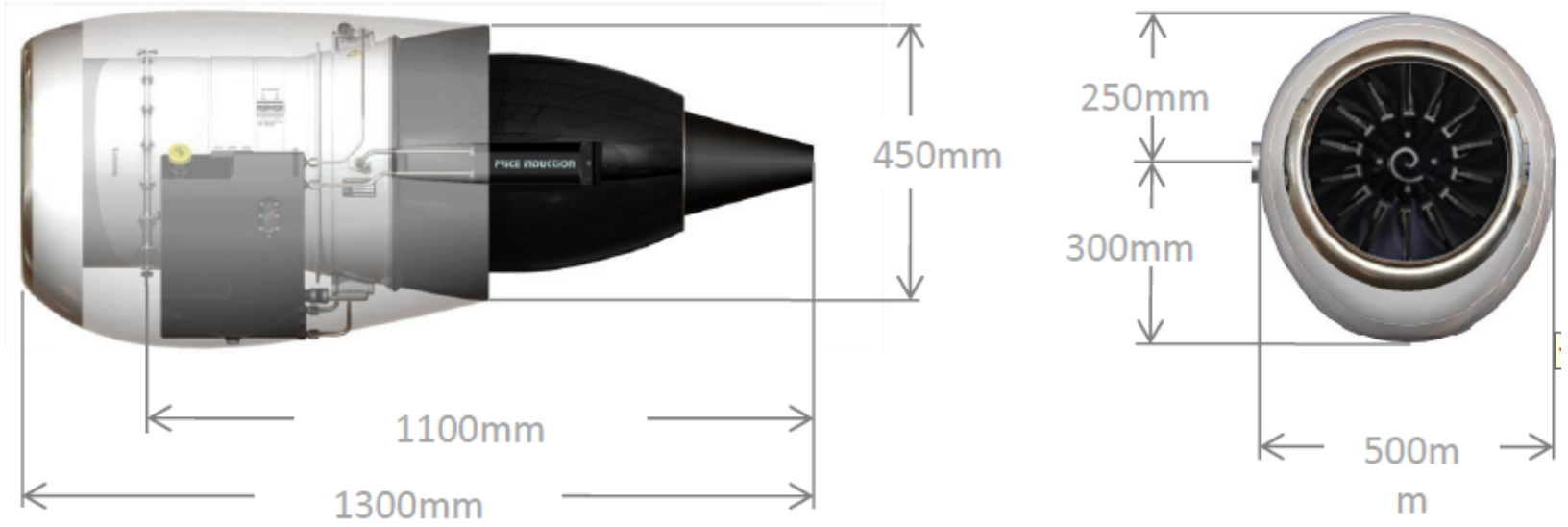

Figure 4: Price-Induction DGEN380 Turbofan Engine Dimensions

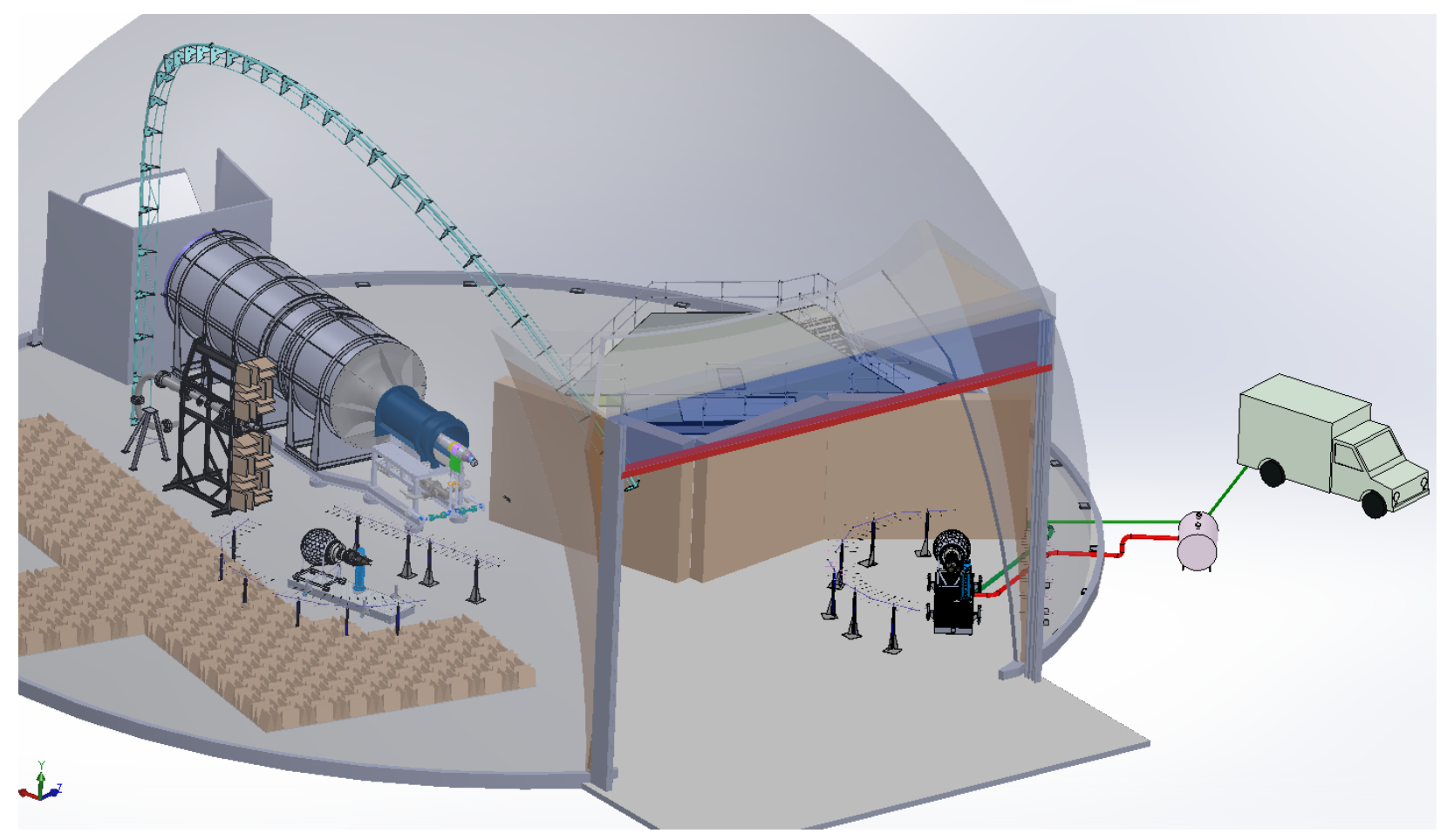

Figure 5: Schematic of DART in the AAPL Showing the Two Test Locations 


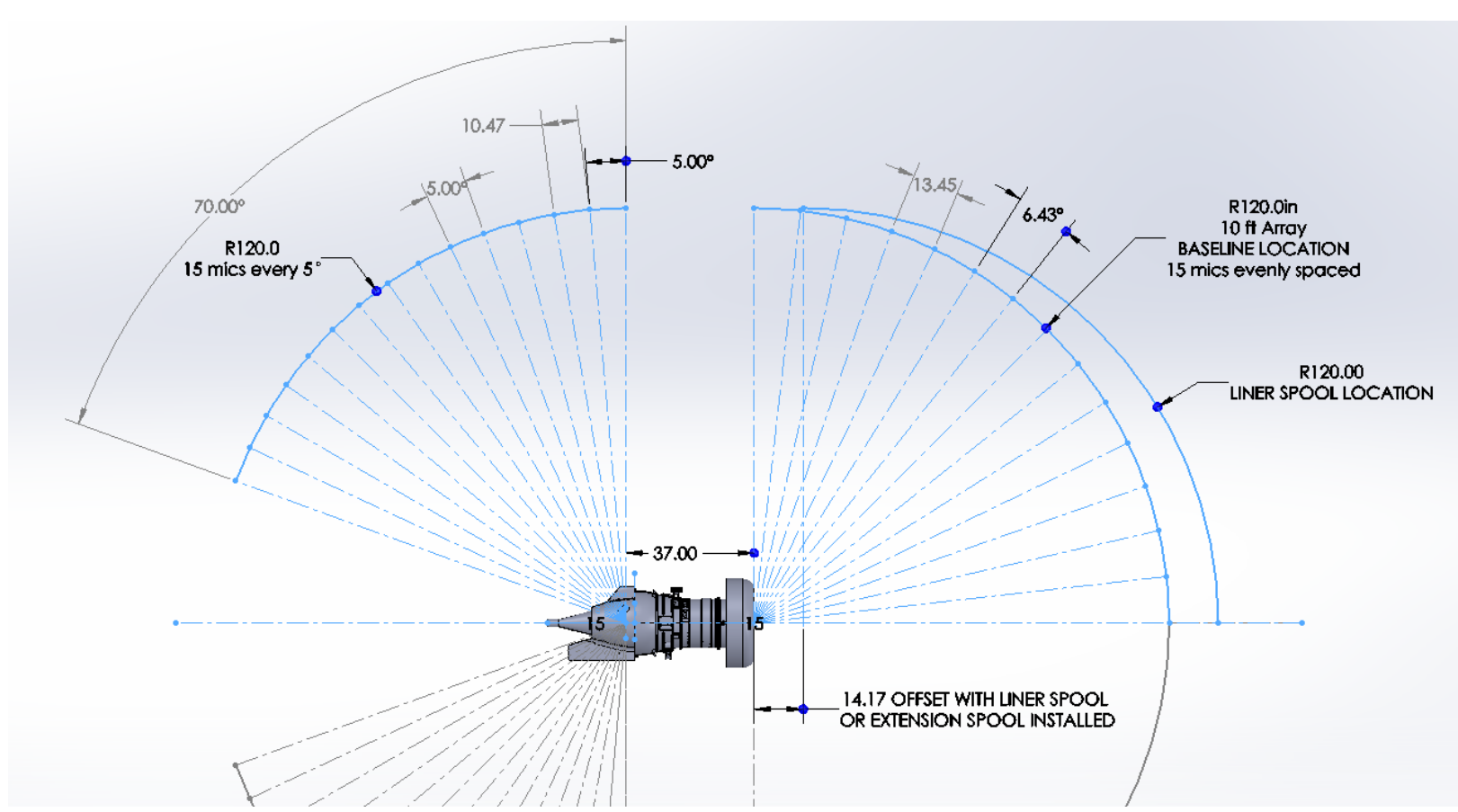

Figure 6: Circular Array about Engine (shown on LHS). Note Adjustment of Forward Arc as Inlet is Extended

TABLE I. DGEN380 Test Settings

\begin{tabular}{||c||c||}
\hline NOMINAL & $\begin{array}{c}\text { Nfan-corr } \\
(\%)\end{array}$ \\
\hline 1 & idle \\
\hline 2 & $50 \%$ \\
\hline 3 & $60 \%$ \\
\hline 4 & $70 \%$ \\
\hline 5 & $80 \%$ \\
\hline 6 & $90 \%$ \\
\hline 7 & $92.5 \%$ \\
\hline 8 & $95.6 \% *$ \\
\hline 9 & $50 \%$ \\
\hline 10 & $95.6 \% *$ \\
\hline 11 & idle \\
\hline
\end{tabular}

Note: *Max Fan speed limited by HPT/EGT temperature limits.
TABLE II. Circular Microphone Array Geometry

\begin{tabular}{||c|c|c|c||}
\hline $\begin{array}{c}\text { Mic } \\
\#\end{array}$ & $\begin{array}{c}\text { Referenced } \\
\text { to Inlet } \\
\text { Plane*(deg) }\end{array}$ & $\begin{array}{c}\text { Mic } \\
\#\end{array}$ & $\begin{array}{c}\text { Referenced } \\
\text { to Exhaust } \\
\text { Plane } \\
\text { (deg) }\end{array}$ \\
\hline 1 & 0 & 16 & 90 \\
\hline 2 & 6.4 & 17 & 95 \\
\hline 3 & 12.9 & 18 & 100 \\
\hline 4 & 19.3 & 19 & 105 \\
\hline 5 & 25.7 & 20 & 110 \\
\hline 6 & 32.1 & 21 & 115 \\
\hline 7 & 38.6 & 22 & 120 \\
\hline 8 & 45 & 23 & 125 \\
\hline 9 & 51.4 & 24 & 130 \\
\hline 10 & 57.9 & 25 & 135 \\
\hline 11 & 64.3 & 26 & 140 \\
\hline 12 & 70.7 & 27 & 145 \\
\hline 13 & 77.1 & 28 & 150 \\
\hline 14 & 83.6 & 29 & 155 \\
\hline 15 & 90 & 30 & 160 \\
\hline
\end{tabular}




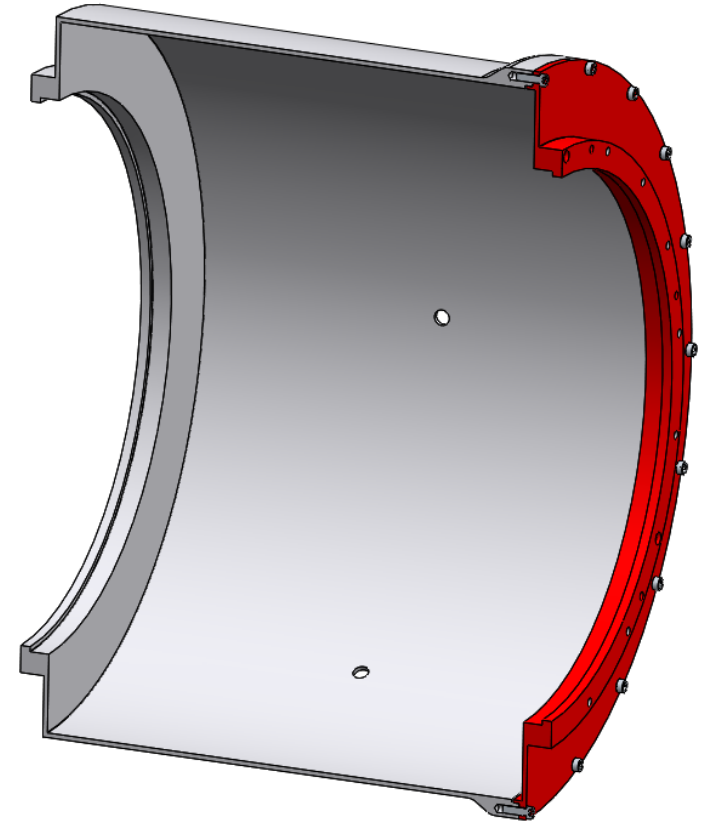

(a) Half View of Liner Holder Spool

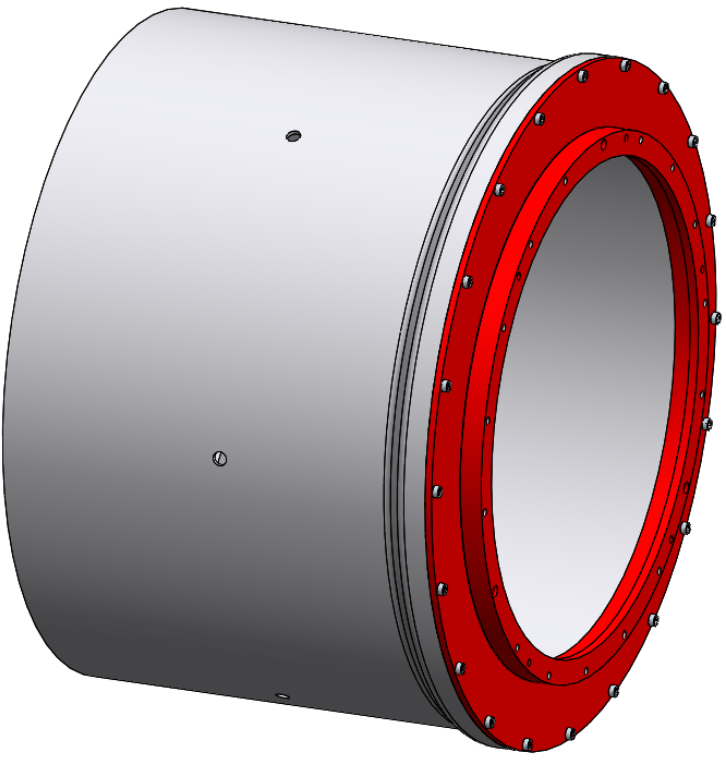

(b) Full View of Liner Holder Spool

Figure 7: Drawings of the Inlet Spool

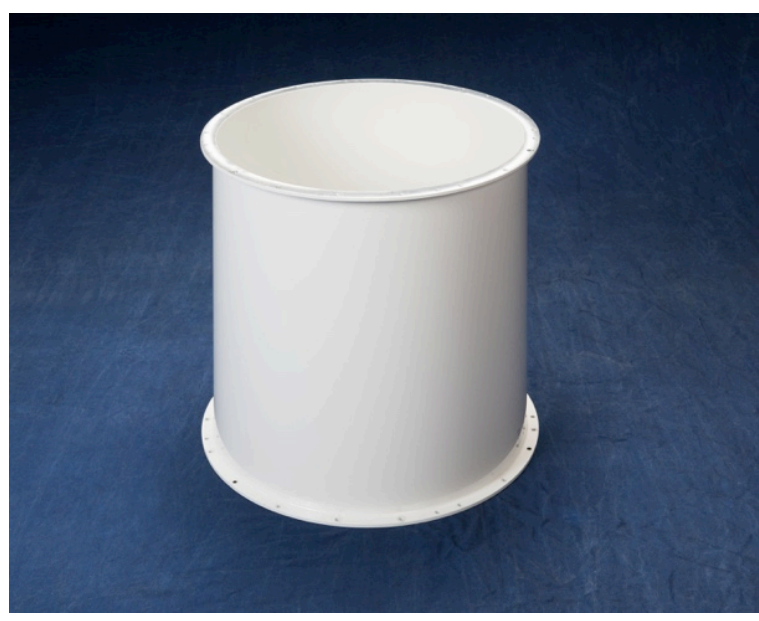

(a) Hardwall Inlet Extension Spool

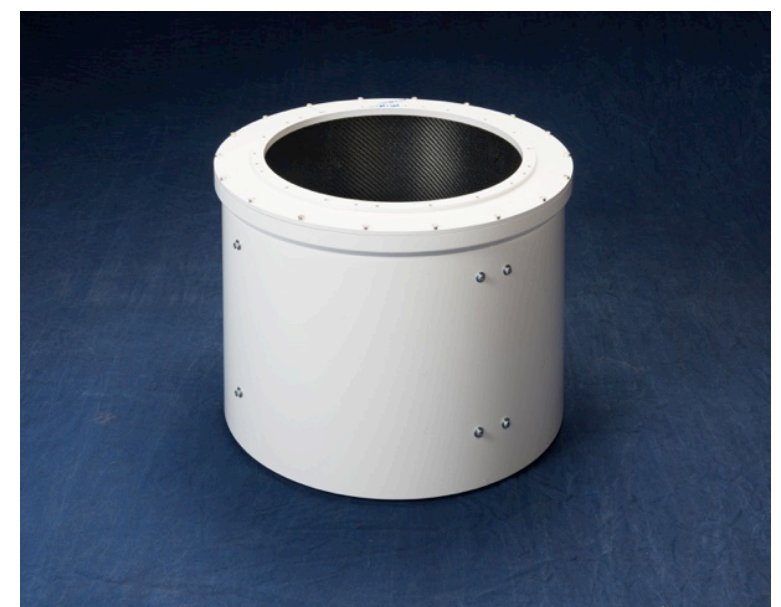

(b) Assembled Liner Holder Spool with core installed

Figure 8: Photos of the Inlet Spool Holder

TABLE III. Liner Configurations Tested.

\begin{tabular}{c|c|c} 
DATE & DGEN Config & ARRAY \\
\hline 1-Aug-17 & Extended Inlet/HW & 10ft arc - LHS \\
\hline 2-Aug-17 & MDOF Liner & 10ft arc - LHS \\
\hline 3-Aug-17 & SDOF Liner & 10ft arc - LHS
\end{tabular}




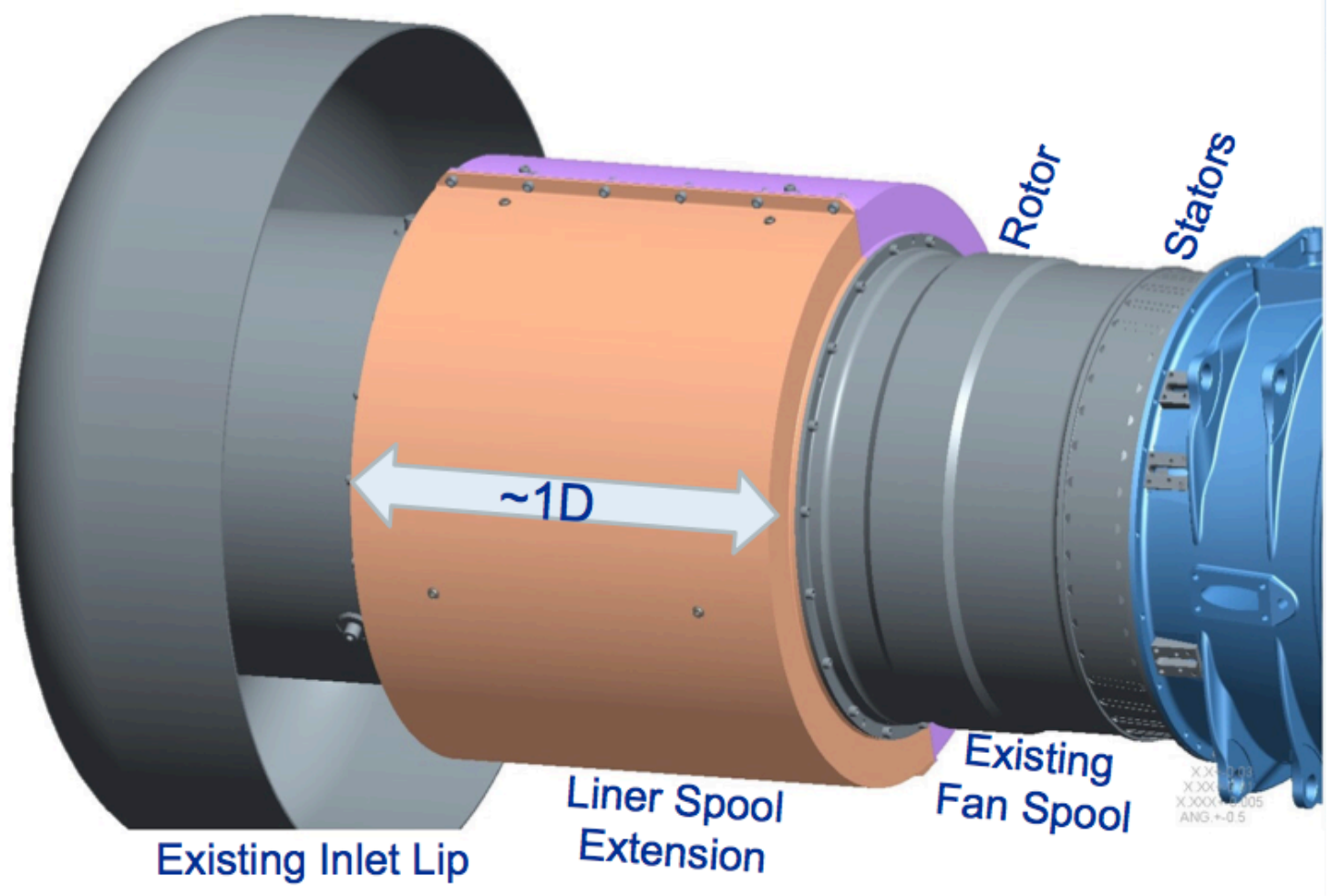

Figure 9: Schematic of the Inlet Spool Holder Installed in the Inlet of the DGEN380

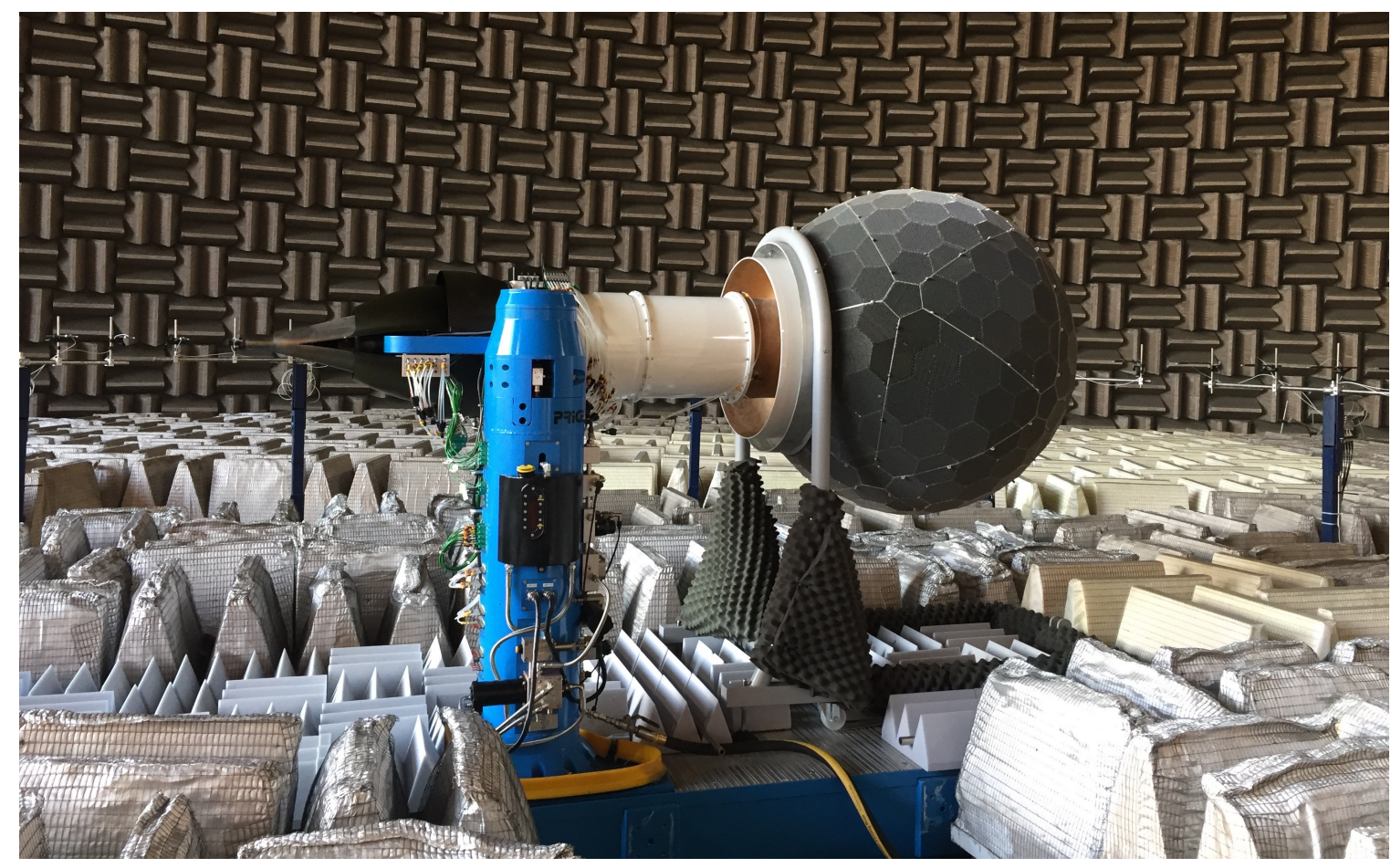

Figure 10: Photo of DART in the Center of AAPL: Hardwall Inlet Extension Shown 


\section{Results}

\section{A. Experimental Results}

The acoustic directivity results as measured by the circular, 10-foot constant radius microphone array for each of the configurations will be presented. The OASPLs integrated over the $100 \mathrm{~Hz}$ to $40 \mathrm{kHz}$ frequency range for both the forward and aft quadrants are presented. The spectral components are separated into total, broadband, and tonal components as described in Reference 24. In addition, the individual tones of the rotating components (fan, compressor, and turbines) and some interaction tones are illustrated. These data are at $92.5 \%$ fan corrected RPM.

Representative spectra (microphone \#9@51.4) for the three configurations are presented in Figure 11. Figure 11a presents the full frequency range. It can be seen that the liner attenuation occurs between 2-14 $\mathrm{kHz}$; though the SDOF liner has a small additional attenuation at $16 \mathrm{kHz}$. At very high frequency, the spectra are unchanged. Figure 11b zooms in on the frequency axis in order to better illustrate the frequencies of interest - also the tones are labeled (see Reference 23). The attenuation from the two liners are very similar and most notable between $2-13 \mathrm{kHz}$.

The OASPL integrated over the $100 \mathrm{~Hz}$ to $40 \mathrm{kHz}$ frequency range is presented in Figure 12. The directivity of the three configurations are presented over both arcs for the total spectral component. The attenuation in the forward quadrant (right arc of polar plot) is apparent, with a consistent 1.5-3.2 $\mathrm{dB}$ attenuation in that arc. As expected, the aft directivity levels are unchanged.

Figure 13 shows the OASPL integrated over the 1 to $10 \mathrm{kHz}$ frequency range for the forward quadrant, and separates the total, broadband, and tonal components. "Zooming-in" on the $1-10 \mathrm{kHz}$ frequency range is more illustrative of the design target bandwidth of the liners. Figure 13a shows the total component. Over this more representative frequency range, the insertion losses of the liners are $\sim 2-6 \mathrm{~dB}$, with a peak attenuation of $5.9 \mathrm{~dB}$ (MDOF) / $6.2 \mathrm{~dB}$ (SDOF) at an angle of $51.4^{\circ}$ relative to the engine centerline. The broadband component peak attenuation (Figure 13b) is $4.3 \mathrm{~dB}$ (MDOF) $/ 4.2 \mathrm{~dB}$ (SDOF) also at $51.4^{\circ}$ with a general range of 1.2-4.3 dB attenuation. As is typical, the tonal component exhibits more variation due to the complex azimuthal interactions of coherent tones (Figure 13c). The range is about $0.5-7.5 \mathrm{~dB}$ attenuation over the arc, with peak attenuations also at 51.4': $7.46 \mathrm{~dB}$ (MDOF) / $6.96 \mathrm{~dB}$ (SDOF). The general observation is the directivity of the two liners insertion loss is completely over the forward quadrant and approximately similar, qualitatively and quantitatively.

The insertion PWL loss of each liner for the range of RPM tested is shown in Figure 14. This is obtained by integrating over the forward microphone array, weighted by the sub-tended area. The insertion loss measured in the forward quadrant for the total, broadband, and tonal components is shown in Figures $14 \mathrm{a}$, 14b, 14c; respectively. The Total PWL insertion loss for the MDOF liner increases as the fan-rpm decreases, mostly due to the variation in tonal attenuation. The broadband PWL insertion is consistent between the two liners across the rpm range $(2.5<\Delta \mathrm{PWL}<3.4)$. For the aft array, the individual spectral insertion losses are shown in Figures 14d, 14e, and 14f. At the lower RPM, a very slight loss is measured, particular at the lower fan speeds, most of which is from the tonal component. It is debatable if these levels are significant, due to tonal variation. A more relevant observation is that the aft levels are unaffected at the primary test point, 92.5\% RPMc-fan.

Several of the tones in the relevant spectral range were extracted from the spectra. The frequencies of these are listed in Table IV. Figure 15 shows the directivity of the extracted tones. The directivity of the $1^{\text {st }}$ four fan harmonics is shown in Figures $15 \mathrm{a}-15 \mathrm{~d}$. F1 is attenuated significantly, as is F3. These are well within the liner design frequency range. F4 is more modestly attenuated, which is on the edge of the liner design bandwidth, so that is a reasonably expected result. F2, however is within the liner design frequency range and should be attenuated, but shows little or no attenuation.

The $1^{\text {st }}$ and $2^{\text {nd }}$ compressor harmonic extracted tonal directivities are shown in Figures $15 \mathrm{e}$ and $15 \mathrm{f} . \mathrm{C} 1$ is within the liner design bandwidth and could be assumed to show attenuation because of its frequency. However, it is not attenuated and, in fact a $4-5 \mathrm{~dB}$ increase is noted between $30^{\circ}$ to $45^{\circ}$ radiated angle. $\mathrm{C} 2$, well outside the liner frequency design, shows a variation in the tone - most likely unrelated to the liners. 
Referring to the earlier plots in this figure, it is apparent the attenuation in the interaction tones is due to a reduction in the fan tone.

The acoustic directivity of the compressor/fan interactions is shown in Figures $15 \mathrm{~g}$ (C1-F1) and $15 \mathrm{~h}$ $(\mathrm{C} 1+\mathrm{F} 1)$. The difference tone $(\mathrm{C} 1-\mathrm{F} 1)$ is attenuated substantially, an expected result as its frequency is between $\mathrm{F} 2$ and $\mathrm{F} 3$. The sum tone $(\mathrm{C} 1+\mathrm{F} 1)$ variations also appears to be due to tonal variation, as it is close in frequency to $\mathrm{F} 4$.

Figure 16a is the forward PWL obtained from the integration of the directivity curves in Figure 15 . The bar graphs confirm the strong attenuation of the fan harmonics (though F2 seems lower than expected) and lack of attenuation of the compressor fundamental. The compressor/fan interaction shows similar results to the fan harmonic, possibly indicating that interaction is dominated by the fan tone. The aft levels are included in Figure 16b. F1 and F3 show slight increases. Potentially this is due to interaction of the liner splice with the fan, radiating aft, though there is no evidence available to support that conjecture. More probably, it is due tone measurement variability.

\section{B. Computational Results}

Overall, the liner designs appear to perform as expected. However, as initial results at the various fan speeds were further analyzed, it became evident that the mean flow Mach number $(M=0.5)$ used in the design process was too high. At the highest corrected fan speed tested $(92.5 \% \mathrm{RPMc})$, flow measurements indicate the mean flow Mach number to be more in the range $M=0.35$. Therefore, the predicted impedances (based on the models in Section III) of the two liners need to be adjusted before direct comparisons could be made at any fan speed. In addition, the Mach number disparity also means that the test points all represent off-design conditions. It should be noted that this does not negate the usefulness of the testing. As mentioned previously, consideration was made to select liners allowing acquisition of sufficient data to demonstrate the validity of the liner design process, and to gain insight that could be used to better optimize liners for future tests with this engine. Therefore, while maximum attenuation may not be achieved, a great deal of information remains to be gained through comparison of predicted and measured results.

A comparison of the predicted mean induct attenuation at the design flow condition $(\mathrm{M}=0.5)$ for both liners is presented in Figure 17. As might be expected, the 3DOF design is predicted to outperform the SDOF design over almost the full frequency range. However, it can be seen that separation between the prediction curves is diminished in the upper frequency range, illustrating the challenge of obtaining larger attenuation in the DART inlet.

In order to perform such comparisons on the 10-ft. arc array, the prediction process used in the liner design must be extended. Recall that induct attenuation was chosen as the cost function for the impedance optimization. As described in Section II, these induct propagation predictions are radiated to arc observer locations using the CDL FW-H (Ffowcs-Williams and Hawkings) duct radiation model. Here, the nacelle inlet plane (exit plane for inlet propagation) is used as a permeable data surface. In keeping with the statistical source model, radiation calculations are performed for each source distribution (random amplitude and phase). Thus, 11 radiation simulations are performed over the full arc array to produce a sample population from which statistical information can be inferred. An example result for the hardwall, SDOF, and $3 \mathrm{DOF}$ inlet configurations at $f=3150 \mathrm{~Hz}$ (one-third octave band center frequency) and 90\% RPMc is presented in Figure 18. In this figure, the directivity patterns are displayed as "normalized" SPL levels (the difference between the SPL and the hardwall peak SPL) since relative levels are of interest. In addition, error bars denoting a range of $+/$ - one standard deviation are included on the hardwall results to illustrate that statistical nature of the result. Similar standard deviation values were obtained for the treated configurations, but are not included for clarity. Note that the same set of modal source distribution (same randomization seed) was used for each configuration. Generally, the attenuation trends in this example appear to follow those in the induct prediction with the 3DOF providing improved performance over the full directivity range.

To further illustrate the flexibility of the statistical source approach, predicted mean attenuation (hardwall SPL - treated SPL) for the SDOF and 3DOF liners are presented in Figure 19 at $3150 \mathrm{~Hz}, 90 \%$ RPMc for 
two different source representations (with and without the plane wave included). Again, the generally improved performance of the $3 \mathrm{DOF}$ is evident. In addition, the effect of including the plane wave in the source specification can be seen in the resulting change in attenuation over various observer angles. A similar result is seen in Figure 20 at $6300 \mathrm{~Hz}$ (one-third octave band center frequency) and 90\% RPMc.

It should be noted that these farfield predictions are based on induct information from the design process and, therefore, the conditions (e.g., RPMc, Mach number, frequency) do not match those corresponding to the tone measurements presented in Figures 15a and 15g. However, the attenuation trends in these examples generally follow those of the measured data for the conditions considered. For example, the strong lobe and corresponding 3DOF benefit near 45 degrees in Figure 19, as well as the $3 \mathrm{DOF}$ benefit over a wide range of directivity angles in Figure 20. Thus, with this capability in place, future work will entail the use of this prediction process over the full fan speed and frequency range for comparison with measured results. Additionally, the effects of modal source distribution will be investigated.

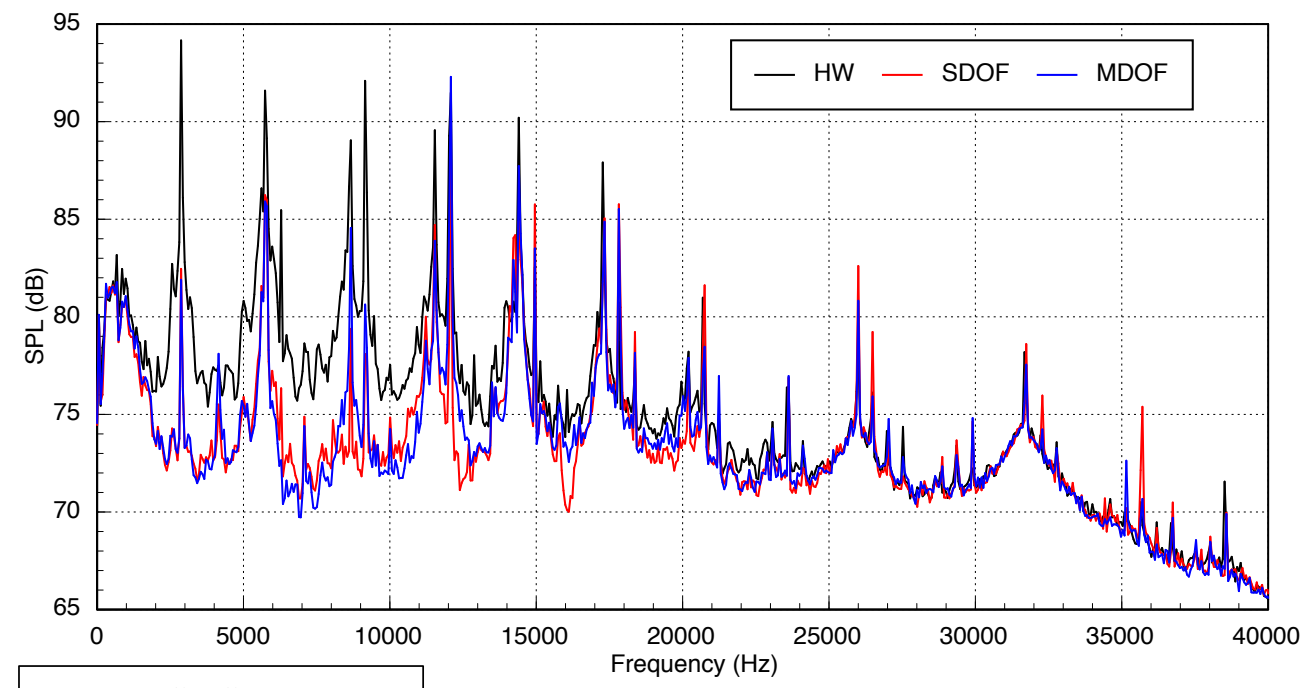

F- Fan C - Compressor

(a) Full Frequency Range

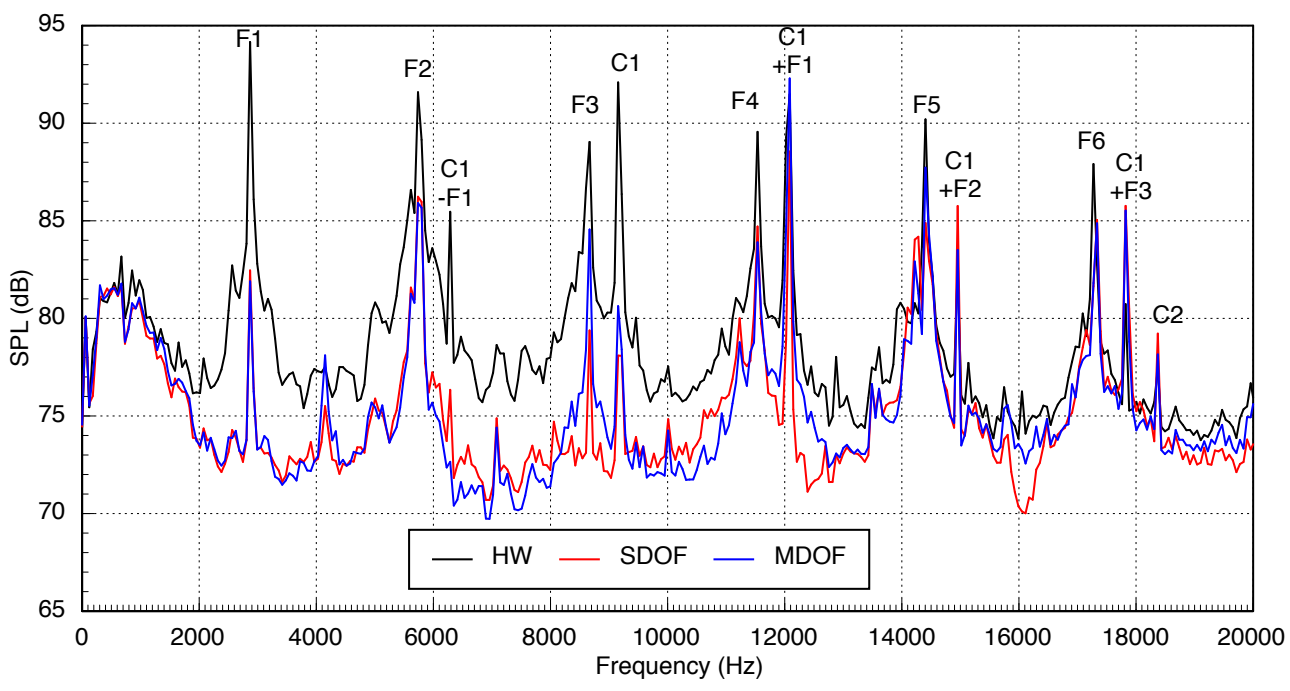

(b) Over Effective Design Range of Liners Highlighting Tonal Components

Figure 11: Representative Spectra (Mic \#9 @ 51.4 ${ }^{\circ}$ ) of the Three Configurations 


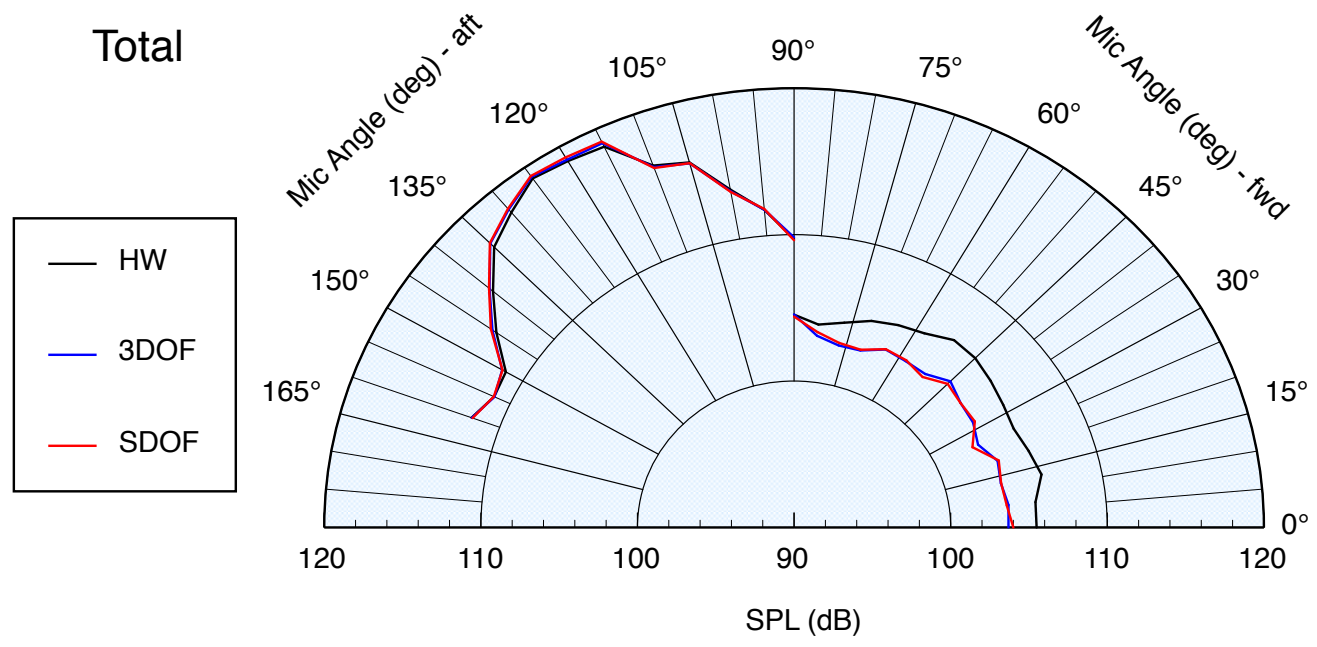

Figure 12: Farfield Acoustic Directivity of the 3 Configurations Tested (Total - OASPL $100 \mathrm{~Hz}$ to $40 \mathrm{kHz}$.)

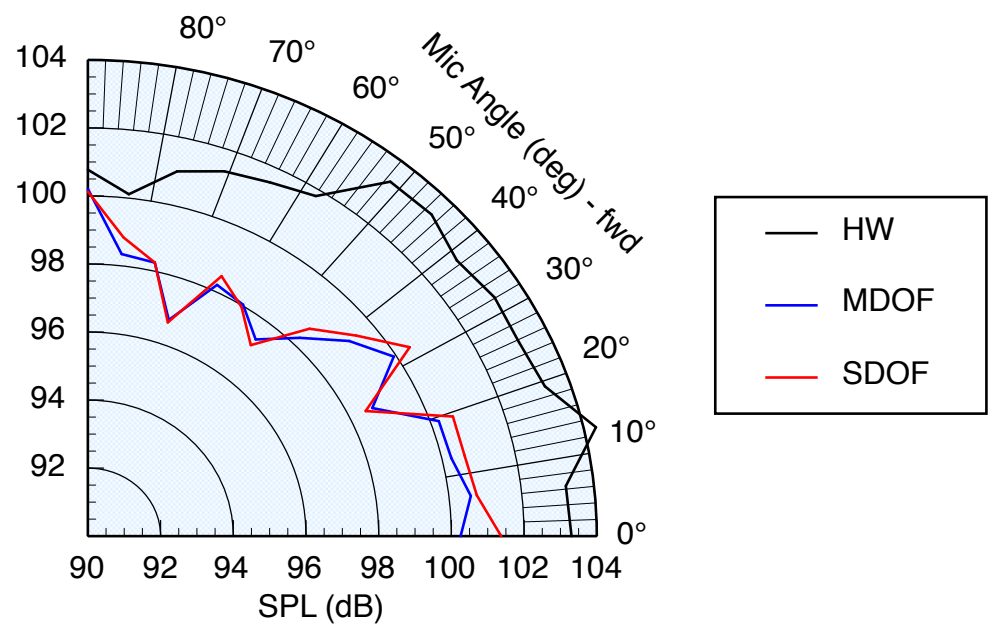

(a) Total - OASPL $1 \mathrm{kHz}$ to $10 \mathrm{kHz}$.

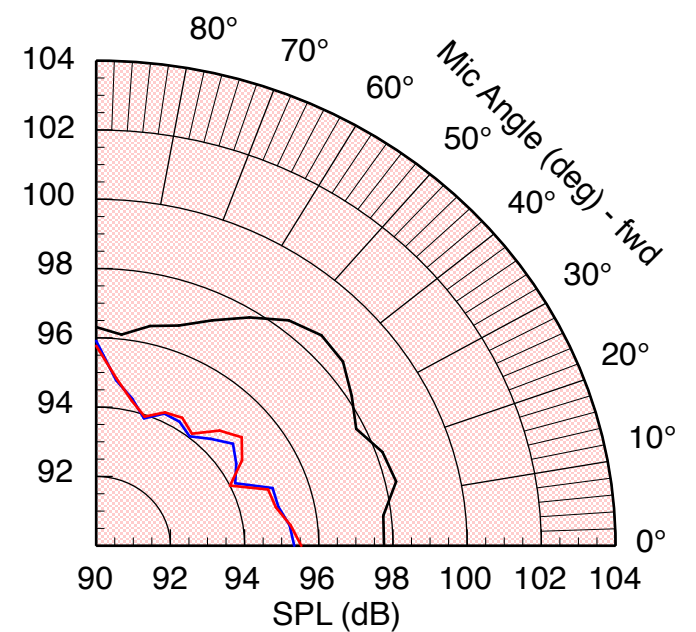

(b) Broadband - OASPL $1 \mathrm{kHz}$ to $10 \mathrm{kHz}$.

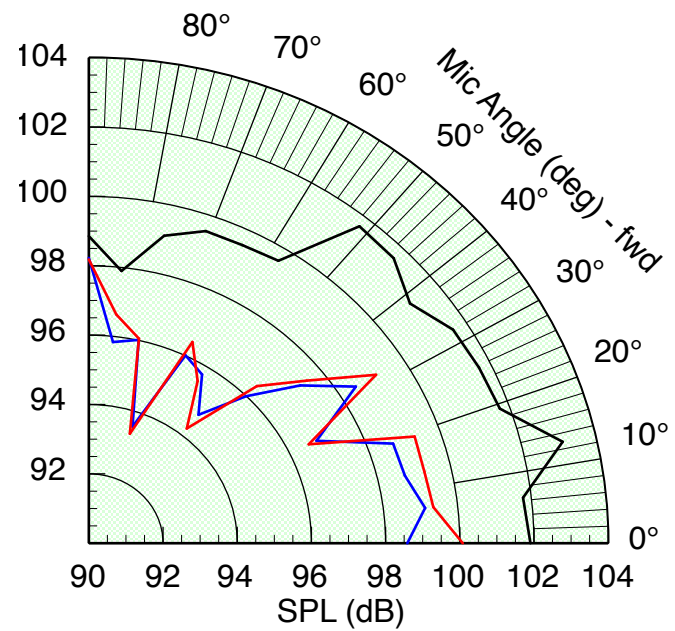

(c) Tonal - OASPL $1 \mathrm{kHz}$ to $10 \mathrm{kHz}$.

Figure 13: Separated Spectral Components Forward Arc Acoustic Directivity of the 3 Configurations Tested 


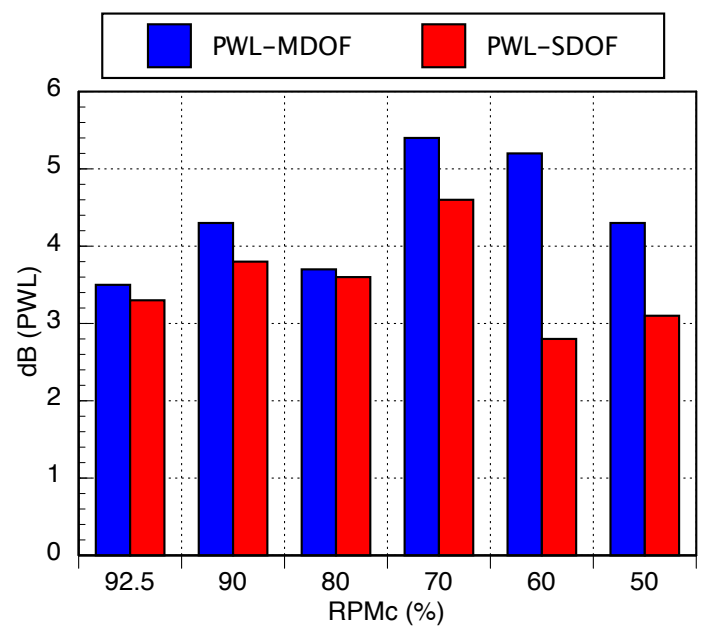

(a) Total PWL Insertion Loss - Forward Arc

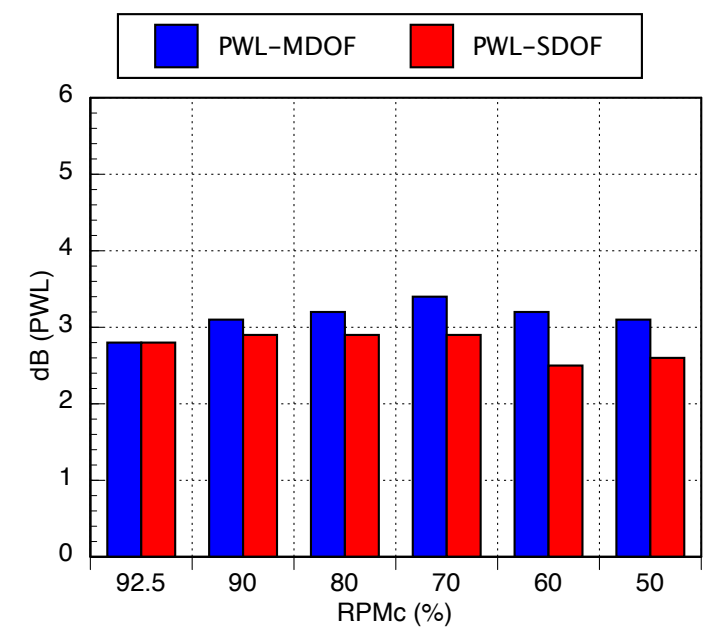

(b) Broadband PWL Insertion Loss - Forward Arc

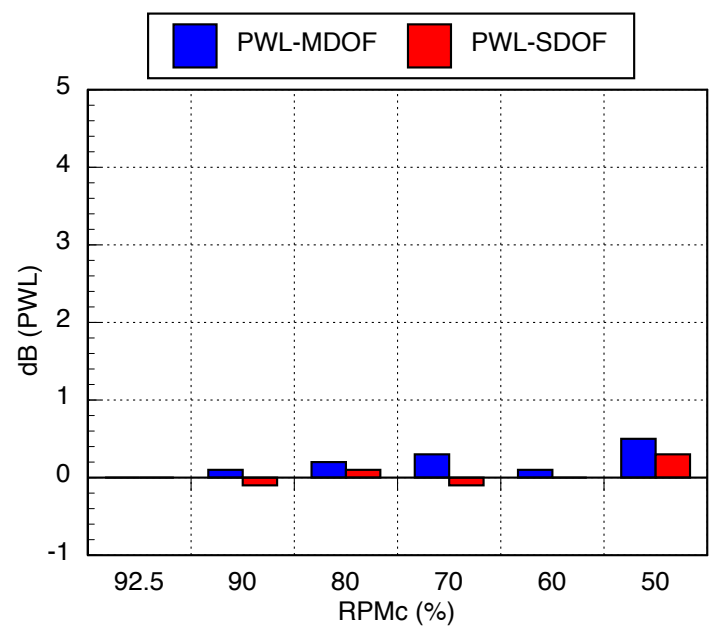

(d) Total PWL Insertion Loss - Aft Arc

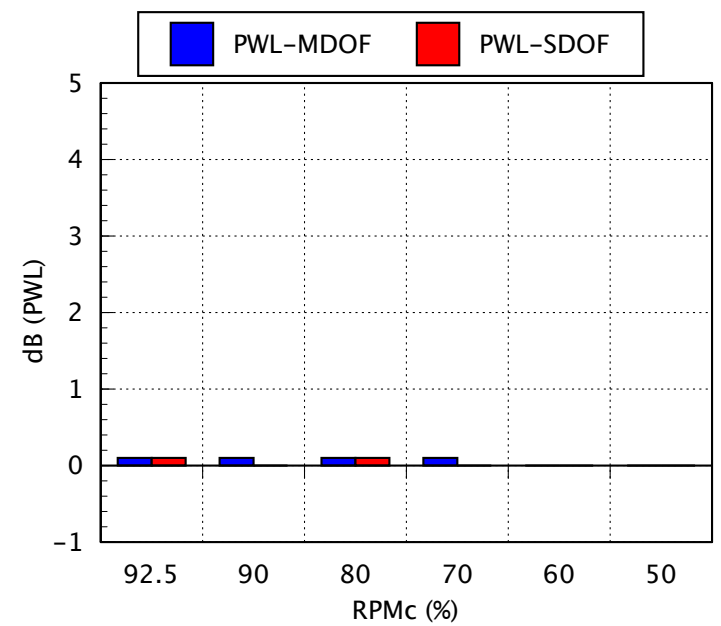

(e) Broadband PWL Insertion Loss - Aft Arc

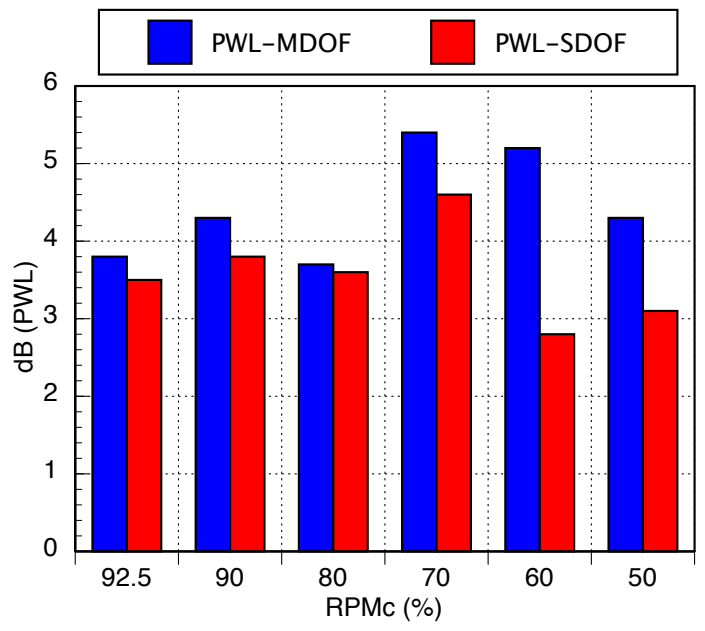

(c) Tonal PWL Insertion Loss - Forward Arc

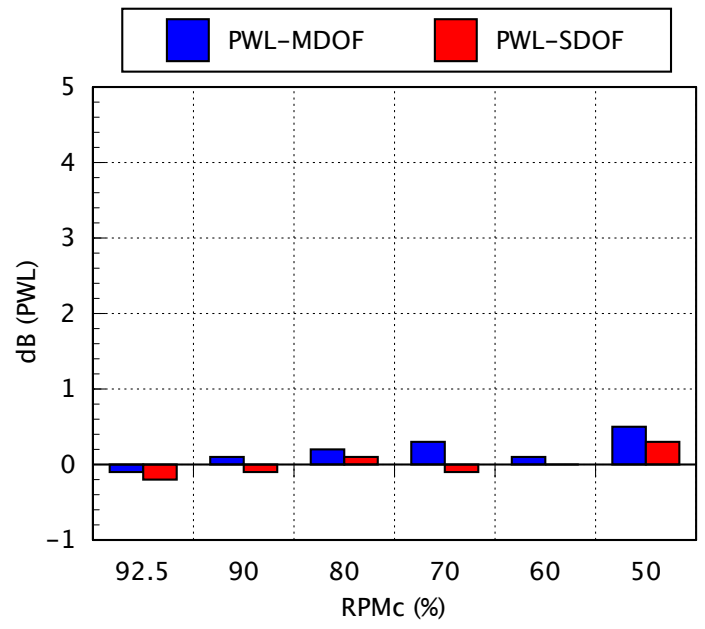

(f) Tonal PWL Insertion Loss - Aft Arc

Figure 14: Insertion Losses vs. RPM 

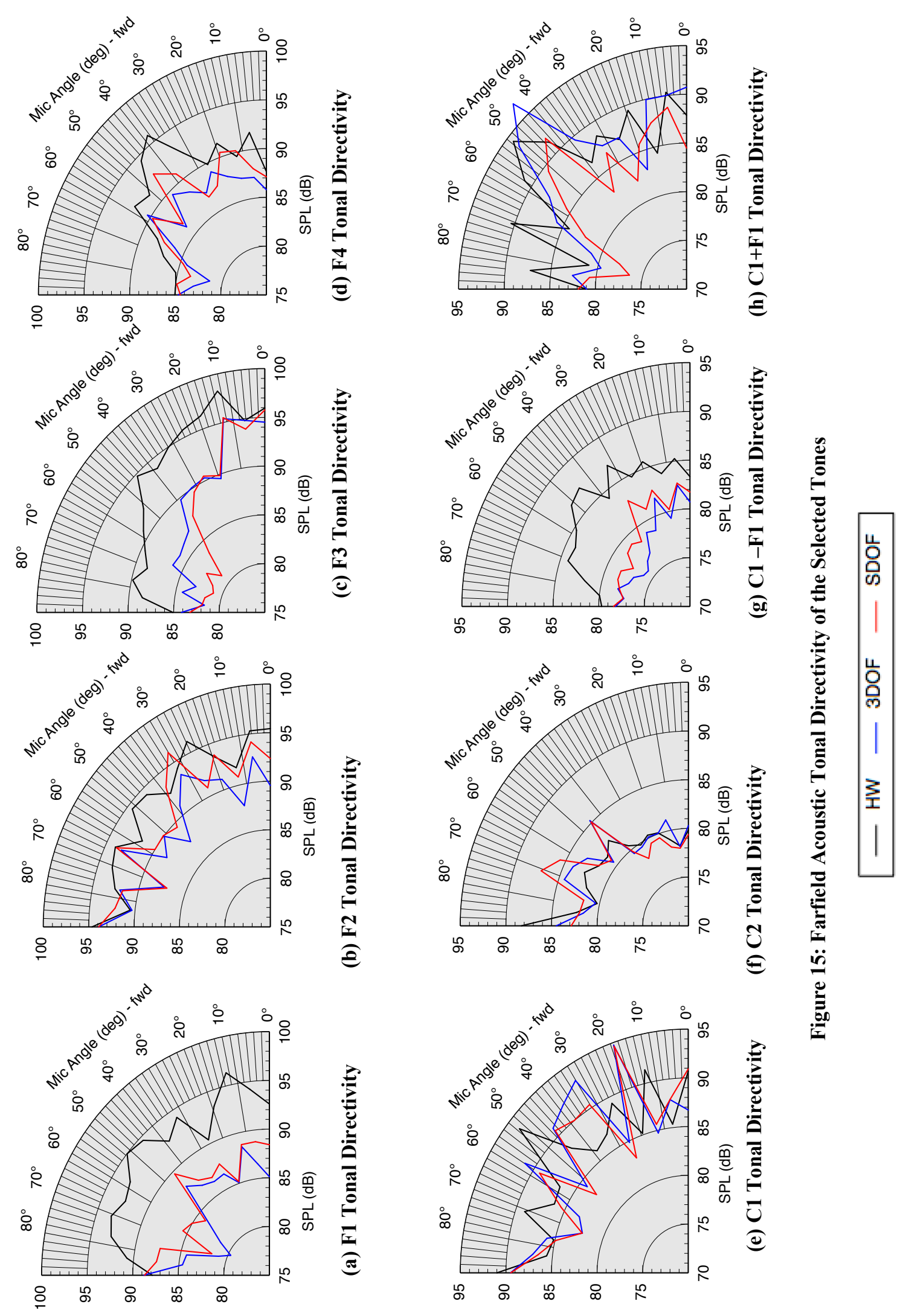
TABLE IV. Frequency of Tonal Components

\begin{tabular}{|c|c|}
\hline Tonal Component & Frequency $(\mathrm{Hz})$ \\
\hline F1 ( $1^{\text {st }}$ Fan Fundamental $)$ & 2,837 \\
\hline F2 ( $2^{\text {nd }}$ Fan Fundamental $)$ & 5,673 \\
\hline F3 ( $3^{\text {rd }}$ Fan Fundamental $)$ & 8,510 \\
\hline F4 ( $4^{\text {th }}$ Fan Fundamental) & 11,347 \\
\hline $\mathrm{C} 1$ ( $1^{\text {st }}$ Compressor Fundamental $)$ & 9,079 \\
\hline C2 (2 $2^{\text {nd }}$ Compressor Fundamental) & 18,158 \\
\hline C1-F1 (Interaction Difference Tone) & 6,242 \\
\hline C1+F1 (Interaction Sum Tone) & 11,915 \\
\hline
\end{tabular}

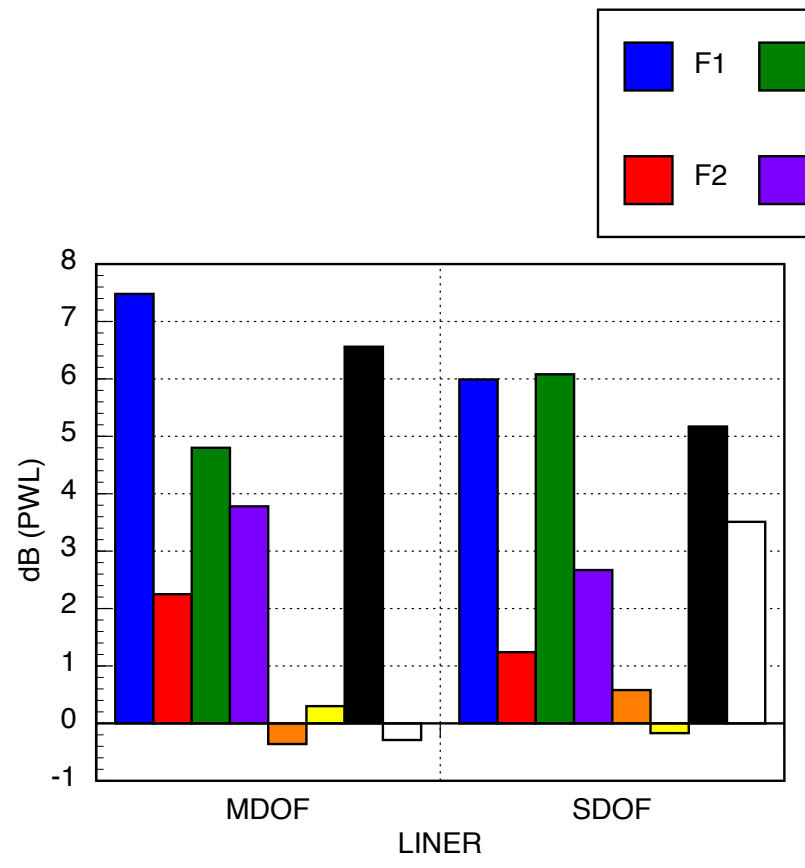

(a) FWD Arc Insertion Loss
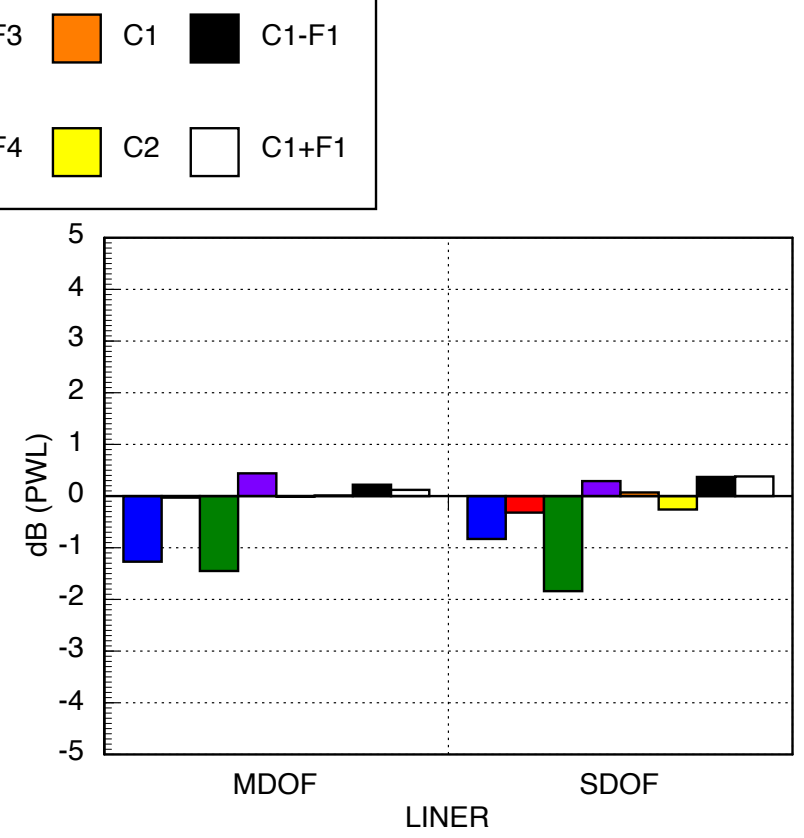

(b) AFT Arc Insertion Loss

Figure 16: Farfield Tonal Acoustic Insertion Loss 


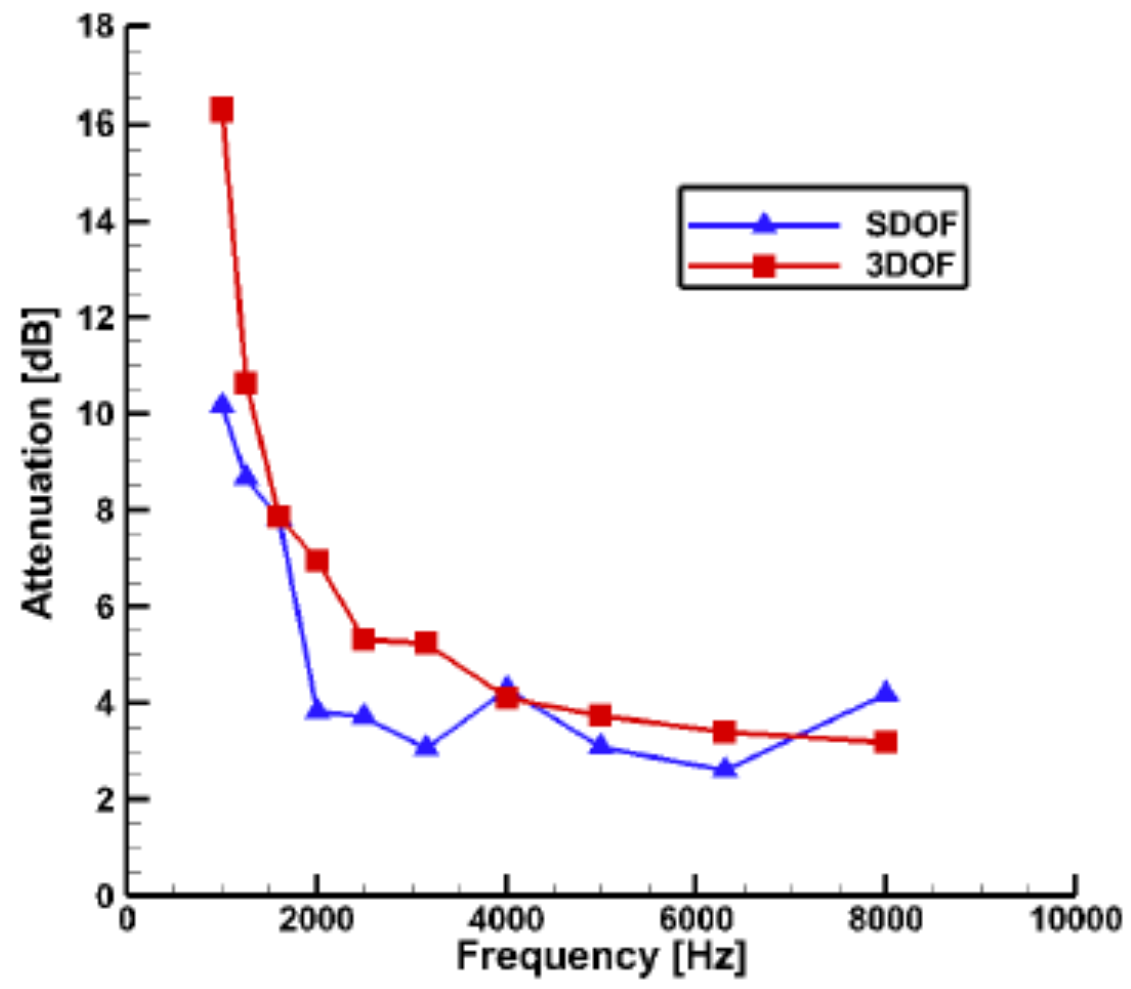

Figure 17: Predicted mean attenuation for the SDOF and 3DOF liners at the design condition $(M=0.5)$

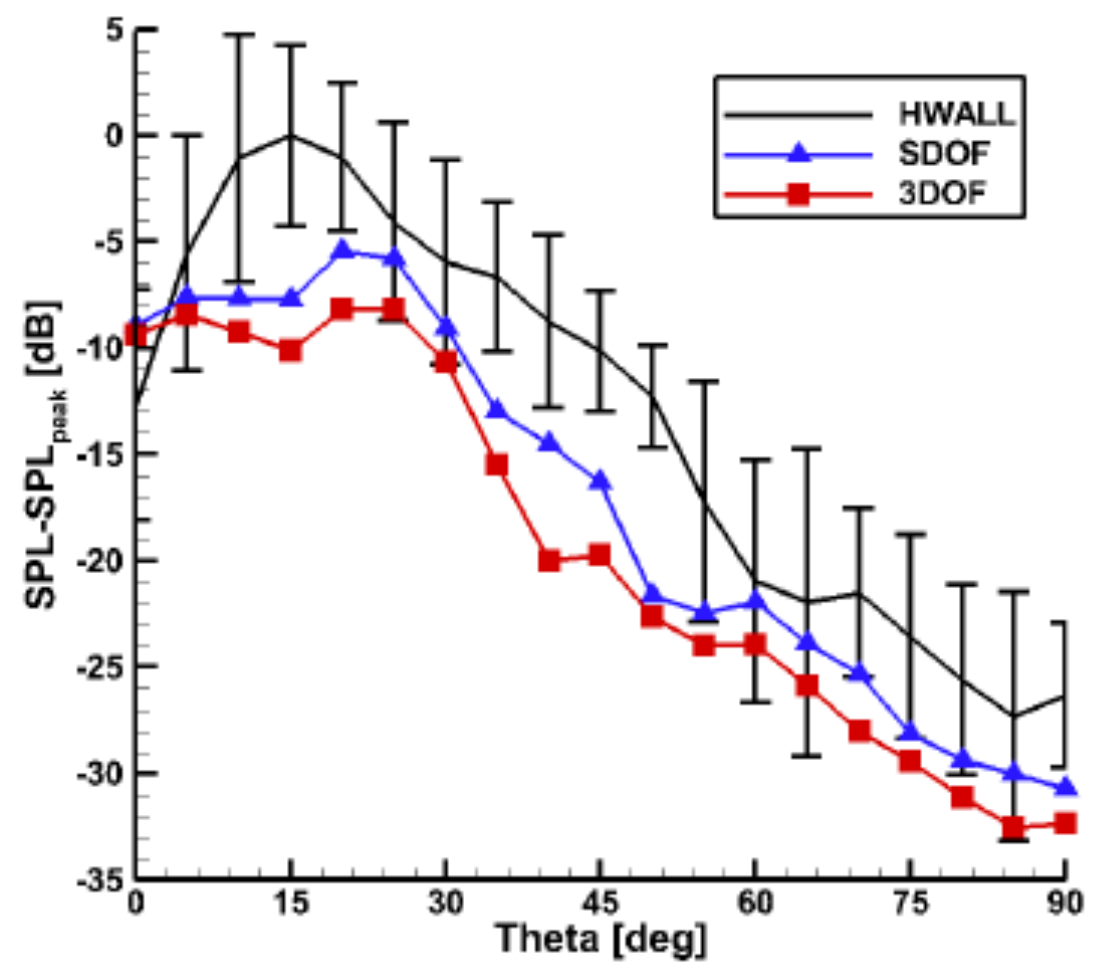

Figure 18: Predicted mean directivity on the $10-\mathrm{ft}$. arc array at $f=3150 \mathrm{~Hz}(90 \% \mathrm{RPMc})$ 


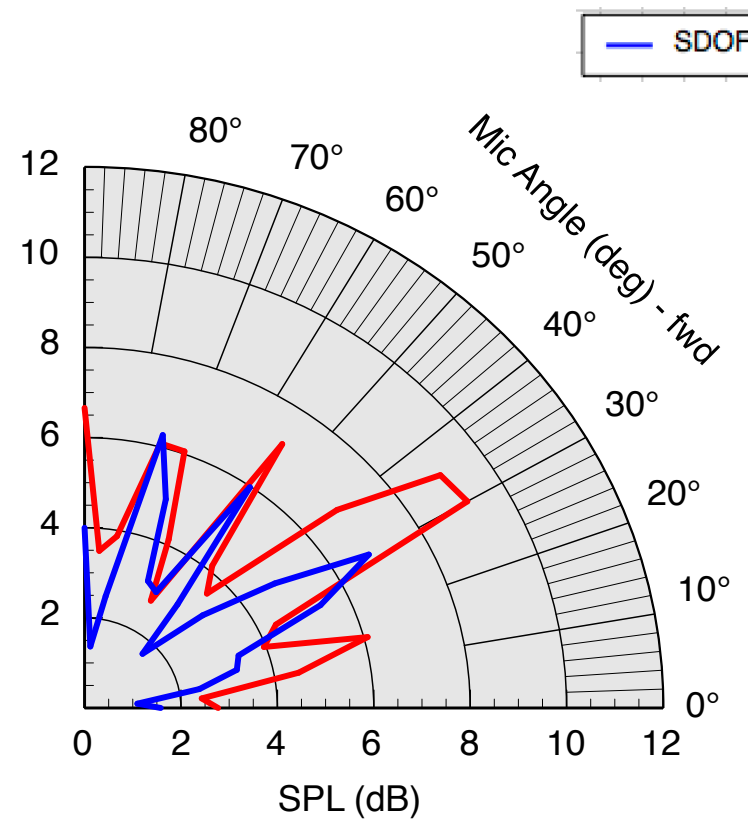

(a) Plane wave included in source specification

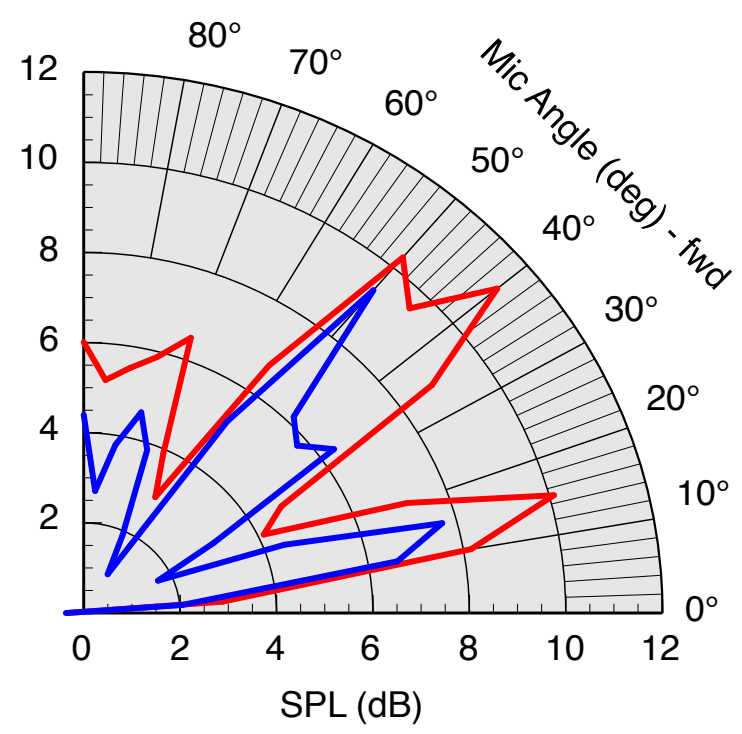

(b) Plane wave neglected in source specification

Figure 19: Predicted mean CDL attenuation on the $10-\mathrm{ft}$. arc array at $f=3150 \mathrm{~Hz}(90 \% \mathrm{RPMc})$

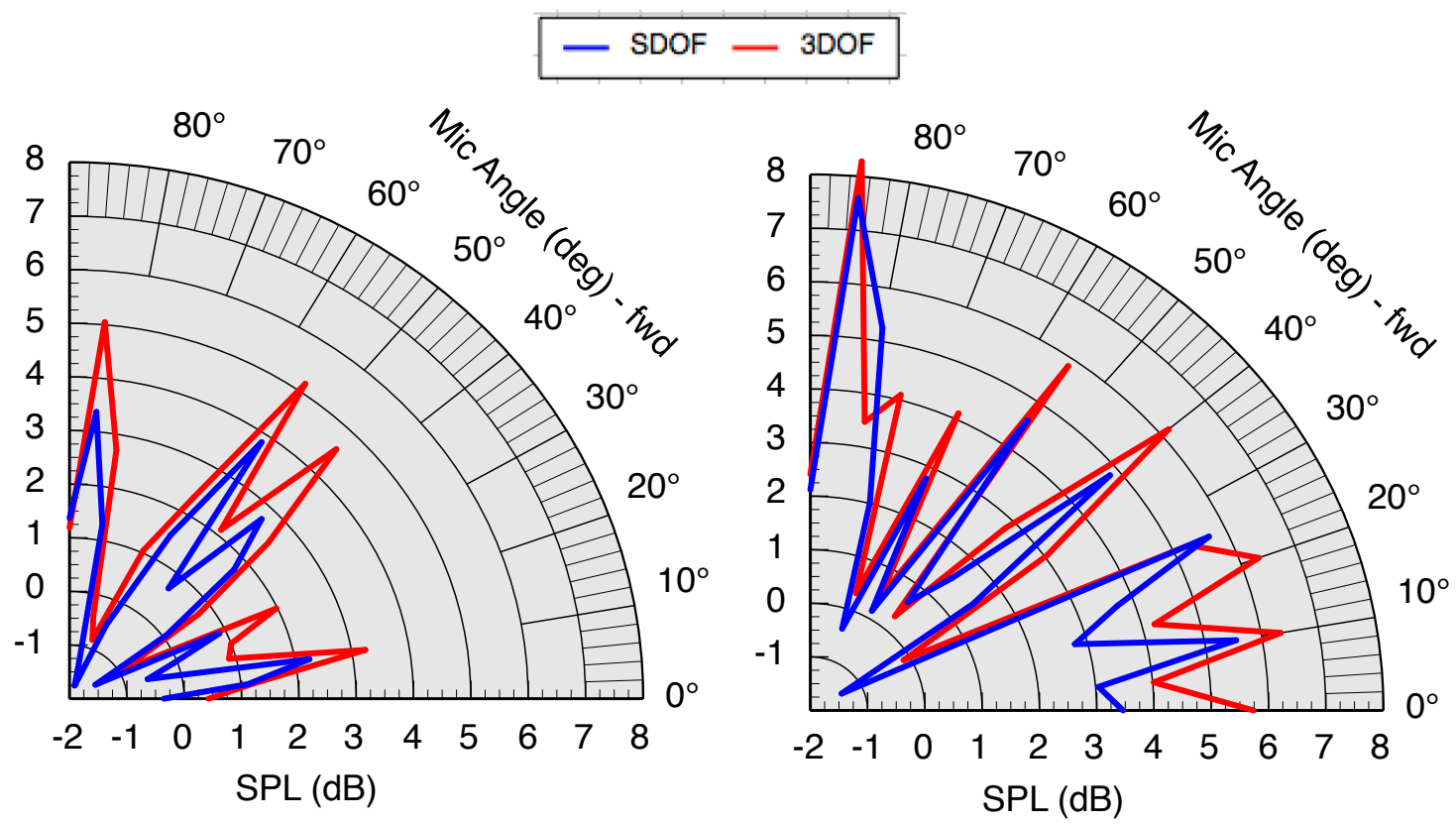

(a) Plane wave included in source specification

(b) Plane wave neglected in source specification

Figure 20: Predicted mean CDL attenuation on the 10-ft. arc array at $f=6300 \mathrm{~Hz}(90 \% \mathrm{RPMc})$ 


\section{Conclusion}

This paper describes extension of a broadband acoustic liner optimization design process to the DART installed in AAPL. Based on induct attenuation predictions, SDOF and 3DOF liners were designed, fabricated, and tested. While the liner design point Mach number fell outside the test range, a great deal of information remains to be gained through comparison of predicted and measured results. A cursory analysis of predicted attenuation results showed them to generally match expected trends (with the 3DOF liner providing slightly improved performance) for the conditions considered. The effects of source distribution on predicted directivity was also illustrated through the flexibility of the statistical source model.

The NASA Glenn Research Center's DGEN Aeropropulsion Research Turbofan (DART) test rig was utilized to evaluate the acoustic performance of an advanced MDOF liner in the NASA Glenn AeroAcoustic Propulsion Laboratory. Acoustic directivity from a farfield microphone array was obtained. A tone separation technique provided tone broadband analysis of a full-scale engine with two independent shafts.

As part of the comparison process, the overall design and evaluation capability was extended such that external observer locations may be included in the optimization process. This enhancement will provide a much wider design space in designing advanced broadband liners. These preliminary results provide further confidence in the design tools, as well as the enhancements made to the overall liner design process. Future work will entail the use of this prediction process over the full fan speed and frequency range for comparison with measured results and provide an excellent opportunity to further evaluate the broadband liner design tools.

\section{ACKNOWLEDGEMENTS}

This work was performed with support from NASA's Advanced Air Transport Technology Project of the NASA Advanced Air Vehicles Program (AAVP). The authors would like to express their appreciation for the efforts of the T-FOME staff at the Aero-Acoustic Propulsion Laboratory. Price Induction is the manufacturer of the DGEN380 turbofan engine and Hexcel, Inc provided the liner cores.

\section{REFERENCES}

\footnotetext{
${ }^{1}$ Nark, D. M. and Jones, M. G., "Broadband Liner Optimization for the Source Diagnostic Test Fan," AIAA Paper 2012-2195, 2012.

${ }^{2}$ Nark, D. M., Jones, M. G., Sutliff, D. L., Ayle, E., and Ichihashi, F., "Improved Broadband Liner Optimization Applied to the Advanced Noise Control Fan," AIAA Paper 2014-3103, 2014.

${ }^{3}$ Nark, D. M., Jones, M. G., and Sutliff, D. L., "Modeling of Broadband Liners Applied to the Advanced Noise Control Fan," AIAA Paper 2015-2693, 2015.

${ }^{4}$ Sutliff, D. L., Jones, M. G., and Nark, D. M., "In-Duct and Far-field Experimental Measurements from the ANCF for the Purpose of Improved Broadband Liner Optimization," AIAA Paper 2014-3231, 2014.

${ }^{5}$ Nark, D. M., Jones, M. G., and Sutliff, D. L., "Further Development and Assessment of a Broadband Liner Optimization Process," AIAA Paper 2016-2784, 2016

${ }^{6}$ Sutliff, D. L., Nark, D. M., and Jones, M. G., "Efficacy of a Multiple Degree of Freedom Acoustic Liner Installed in the Bypass of a Scale Model High Speed Fan," AIAA Paper 2016-3005, 2016.

${ }^{7}$ Miller, C.J., Stephens, D.B., Sutliff, D.L., and Dussling J., "Acoustic Testing of a High Tip Speed Fan with Bypass-Duct Liners", NASA/TM-2017-219155.

${ }^{8}$ Gerhold, C. H., Brown, M. C., and Jones, M. G., "Segmented Liner to Control Mode Scattering," AIAA Paper 2013-2078, 2013.

9 Jones, M. G., Watson, W. R., and June, J. C., "Optimization of Microphone Locations for Acoustic Liner Impedance Eduction," AIAA Paper 2015-3271, 2015

${ }^{10}$ Nark, D. M., Jones, M. G., Schiller, N. H., and Sutliff, D. L., "Broadband Inlet Liner Design for the DGEN Aeropropulsion Research Turbofan," AIAA Paper 2018-3608, 2018.
} 
${ }^{11}$ Sutliff, D.L., "Acoustic Directivity of the DGEN Aero-propulsion Research Turbofan at Multiple Farfield Array Locations", AIAA-2018-3279.

12 Brown, C. and Sutliff, D. L., "DGEN Aeropropulsion Research Turbofan (DART): Lossless Projection of Measured Engine Noise Spectra to a 1-Foot-Radius Arc", AIAA-2018-3280.

${ }^{13}$ Nark, D. M., Jones, M. G., Schiller, N. H., and Sutliff, D. L., "Broadband Inlet Liner Design for the DGEN Aeropropulsion Research Turbofan," AIAA Paper 2018-3608, 2018.

${ }^{14}$ Nark, D. M., "Assessment of Radiated Fan Noise Prediction Capabilities using Static Engine Test Data," AIAA Paper 2011-2807, 2011

15 Jones, E., Oliphant, T., Peterson, P., et al., "SciPy: Open source scientific tools for Python," 2001 -.

${ }^{16}$ Jones, M. G., Howerton, B. M., and Ayle, E., "Evaluation of Parallel-Element, Variable-Impedance, Broadband Acoustic Liner Concepts," AIAA Paper 2012-2194, 2012.

17 Parrott, T. L. and Jones, M. G., "Parallel-Element Liner Impedances for Improved Absorption of Broadband Sound in Ducts," Noise Control Engineering Journal, Vol. 43, No. 6, 1995, pp. 183-195

${ }^{18}$ Motsinger, R. E. and Kraft, R. E., "Design and Performance of Duct Acoustic Treatment: Aeroacoustics of Flight Vehicles; Chapter 14, Vol. 2: Noise Control," NASA RP 1258, August 1991.

19 Jones, M. G., Parrott, T. L., and Watson, W. R., "Uncertainty and Sensitivity Analyses of a Two-Parameter Impedance Prediction Model," AIAA Paper 2008-2928, 2008.

${ }^{20}$ Parrott, T. L. and Jones, M. G., "Assessment of NASA's Aircraft Noise Prediction Capability, Chapter 6: Uncertainty in Acoustic Liner Impedance Measurement and Prediction," NASA TP 2102-215653, July 2012

${ }^{21}$ Jones, M. G., Howerton, B. M., and Ayle, E., "Evaluation of Parallel-Element, Variable-Impedance, Broadband Acoustic Liner Concepts," AIAA Paper 2012-2194, 2012.

${ }^{22}$ Cooper, B.A., "A Large Hemi-Anechoic Chamber Enclosure for Community-Compatible Aeroacoustic Testing of Aircraft Propulsion Systems", Journal of the Institute of Noise Control Engineering of the USA, Jan/Feb 1994.

${ }^{23}$ Sutliff, D.L., Brown, C.A., Bayon, B., and Sree, D., "Farfield Acoustic Characteristics of the DGEN380 Turbofan Engine as Measured in the NASA Glenn Aero-Acoustic Propulsion Laboratory", AIAA-2016-3006.

${ }^{24}$ Sree, D., "A novel signal processing technique for separating tonal and broadband noise components from counter-rotating open-rotor acoustic data", International Journal of Aeroacoustics, vol. 12, no. 1+2, pp. 169-188, 2013.

${ }^{25}$ Sree D. and Stephens, D.B., "Tone and Broadband Noise Separation from Acoustic Data of a Scale-Model Counter-Rotating Open Rotor", in 20th AIAA/CEAS Aeroacoustics Conference, Atlanta Georgia, 16-20 June, 2014. 